\title{
ON THE RATE OF CONVERGENCE OF BINOMIAL GREEKS
}

\author{
SAN-LIN CHUNG \\ WEIFENG HUNG \\ HAN-HSING LEE* \\ PAI-TA SHIH
}

This study investigates the convergence patterns and the rates of convergence of binomial Greeks for the CRR model and several smooth price convergence models in the literature, including the binomial Black-Scholes (BBS) model of Broadie M and Detemple J (1996), the flexible binomial model (FB) of Tian YS (1999), the smoothed payoff (SPF) approach of Heston S and Zhou G (2000), the GCRR-XPC models of Chung SL and Shih PT (2007), the modified FB-XPC model, and the modified GCRR-FT model. We prove that the rate of convergence of the CRR model for computing deltas and gammas is of order $O(1 / n)$, with a quadratic error term relating to the position of the final nodes around the strike price. Moreover, most smooth price convergence models generate deltas and gammas with monotonic and smooth convergence with order $O(1 / n)$. Thus, one can apply an extrapolation formula to enhance their accuracy. The numerical results show that placing the strike price at the center of the tree seems to

\footnotetext{
We thank the comments of Keng-Yu Ho, Yaw-Huei Wang, Chung-Ying Yeh, and the editor Bob Webb. We are particularly grateful for the suggestions and comments of an anonymous referee. The financial support of National Science Council of Taiwan and the research assistance of Wei-Che Tsai are acknowledged.

*Correspondence author, Graduate Institute of Finance, National Chiao Tung University, No. 1001 University Road, Hsinchu 300, Taiwan. Tel: +886-3-5712121\#57076, Fax: +886-3-5733260, e-mail: hhlee@mail.nctu.edu.tw
}

Received October 2009; Accepted July 2010

- San-Lin Chung and Pai-Ta Shih are at the Department of Finance, National Taiwan University, Taipei, Taiwan.

- Weifeng Hung is at the Department of Finance, Feng-Chia University, Taichung, Taiwan.

- Han-Hsing Lee is at the Graduate Institute of Finance, National Chiao Tung University, Hsinchu, Taiwan. 
enhance the accuracy substantially. Among all the binomial models considered in this study, the FB-XPC and the GCRR-XPC model with a two-point extrapolation are the most efficient methods to compute Greeks. (C) 2010 Wiley Periodicals, Inc. Jrl Fut Mark 31:562-597, 2011

\section{INTRODUCTION}

Binomial methods, developed by Cox, Ross, and Rubinstein (1979, CRR thereafter), are well known for their flexibility and efficiency in calculating option prices. One stream of the literature modifies the lattice or tree type to improve the accuracy and efficiency for computing option prices. The pricing errors in the binomial models are mainly due to "distribution error" and "nonlinearity error" (see Figlewski \& Gao, 1999, for thorough discussions). Within the literature, there are many proposed solutions that reduce the distribution error and/or nonlinearity error. For example, Broadie and Detemple (1996) and Heston and Zhou (2000) modified binomial models by replacing the binomial prices one period prior to the end of the tree by the Black-Scholes values, or by smoothing payoff functions at maturity, and then computing the rest of binomial prices as usual. The other improved lattice approaches include Omberg (1988), Leisen and Reimer (1996), Figlewski and Gao (1999), Tian (1999), and Chung and Shih (2007). ${ }^{1}$

In this study, we focus on recent binomial models whose binomial option prices converge to the "true" value monotonically and smoothly. In other words, the pricing errors of these binomial option prices are of the same sign and decrease at a known rate as the number of time steps $(n)$ increases. $^{2}$ Thus, their accuracy for pricing options can be enhanced using the standard Richardson extrapolation technique. Specifically, the binomial models investigated in this study include the binomial Black-Scholes (BBS) model of Broadie and Detemple (1996), the flexible binomial model (FB) of Tian (1999), the smoothed payoff (SPF) approach of Heston and Zhou (2000), the GCRR-XPC models of Chung and Shih (2007), the modified FB-XPC model, and the modified GCRR-FT model. ${ }^{3}$

\footnotetext{
${ }^{1}$ Omberg (1988) developed a family of efficient multinomial models by applying the highly efficient GaussHermite quadrature to the integration problem (e.g. $N\left(d_{1}\right)$ in the Black-Scholes formula) presented in the option pricing formulae. Leisen and Reimer (1996) modified the sizes of up- and down-movements by applying various normal approximations (e.g. the Camp-Paulson inversion formula) to the binomial distribution derived in the mathematical literature. Figlewski and Gao (1999) proposed the so-called adaptive mesh method, which sharply reduces nonlinearity error by adding one or more small sections of fine high-resolution lattice onto a tree with coarser time and price steps. Tian (1999) and Chung and Shih (2007) added a stretch parameter $(\lambda)$ into the CRR model to fine-tune the lattice structure so as to efficiently price options.

${ }^{2}$ Binomial models with the smooth and monotonic convergence property are the most accurate ones in the recent literature because their accuracy can be substantially improved by applying the Richardson extrapolation technique (Chang, Chung, \& Stapleton, 2007).

${ }^{3}$ These models will be reviewed in Section 2. We thank an anonymous referee for suggesting the FB-XPC model in which the lattice is set up in a way that the strike price is at the center of the final nodes.
} 
Although the above models have been widely applied to price options, their convergence patterns and rates of convergence for calculating hedge ratios are not known. ${ }^{4}$ Actually, the asymptotic property of binomial Greeks as $n$ increases is not well studied even for the standard CRR model. To fill the gap in the literature, we apply the extended tree method proposed by Pelsser and Vorst (1994) to calculate Greeks under the CRR model and these smooth price convergence models. ${ }^{5}$

We first prove that by using the extended tree method, the rate of convergence of the CRR model for computing delta and gamma is of order $O(1 / n)$, with a quadratic error term relating to the position of the final nodes around the strike price (see Theorem 1 of this study for details). We then show that the rates of convergence of the binomial Greeks under these six smooth price convergence models are also of the order $O(1 / n)$.

Moreover, our numerical results indicate that most smooth price convergence models can also generate binomial deltas and gammas with monotonic and smooth convergence. Thus, one can apply the extrapolation formula to enhance the accuracy of these hedge ratios. Among all the binomial models considered in this study, the FB-XPC and the GCRR-XPC model are the most efficient methods for the calculation of deltas and gammas for European and American options when a two-point extrapolation formula is used. The results suggest that placing the strike price at the center of the tree can enhance the accuracy substantially.

The rest of the study is organized as follows. Section 2 briefly reviews the binomial models considered in this study. The rates of convergence of applying the extended tree method to the CRR model, the SPF model, and the GCRRXPC model are proved in Section 3, along with a discussion of the extrapolation formula. Section 4 presents the numerical results of various binomial models for the evaluations of deltas and gammas. Section 5 concludes the study.

\section{REVIEWS OF THE BINOMIAL OPTION PRICING MODELS}

We assume that the Black-Scholes economy holds and thus options can be valued as if the investors are risk-neutral. In other words, the options are priced

\footnotetext{
${ }^{4}$ The only exception is Chung and Shackleton (2002) who show the convergence patterns of the BBS model for computing hedge ratios.

${ }^{5}$ Numerical differentiation formulae (e.g. $\Delta=[C(S+\Delta S)-C(S-\Delta S)] / 2 \Delta S$, where $C(x)$ is the binomial option price when the underlying asset price is $x$ ) can also be applied to these binomial models for the calculations of Greeks. However, by using numerical differentiation formulae, it needs to construct two binomial trees to calculate delta and to construct three binomial trees to calculate gamma. Thus, it takes more time to calculate Greeks. Besides, the numerical results show that the convergent patterns of binomial Greeks using numerical differentiation formulae are not smooth and monotonic. Thus, we do not apply numerical differentiation formulae in this study.
} 
under the risk-neutral measure where stock price follows a geometric Brownian motion given by

$$
\frac{d S}{S}=(r-q) d t+\sigma d Z
$$

where $S$ is the stock price, $r$ is the risk-free rate, $q$ is the dividend yield, and $\sigma$ is the instantaneous volatility of $S$.

The binomial option pricing model was first developed by Cox et al. (1979) and Rendleman and Bartter (1979). Consider the pricing of an option maturing at time $T$. In an $n$-period binomial model, the time to maturity $[0, T]$ is partitioned into $n$ equal time steps $\Delta t=T / n$. If the stock price is $S$ in this period, then it is assumed to jump either upward to $u S$ with probability $p$ or downward to $d S$ with probability $1-p$ in the next period, where $0<d<e^{(r-q) \Delta t}<u$ and $0<p<1$. The binomial model is completely determined by the jump sizes $u$ and $d$ and the risk-neutral probability $p$.

In the traditional CRR model, the following three conditions are utilized to determine $u, d$, and $p$.

$$
\begin{gathered}
p S u+(1-p) S d=S e^{(r-q) \Delta t} \\
p u^{2}+(1-p) d^{2}-[p u+(1-p) d]^{2}=\sigma^{2} \Delta t \\
u d=1 .
\end{gathered}
$$

The first two conditions are used to match the mean and variance of the stock price in the next period, and the third condition is imposed arbitrarily by CRR. With these three conditions, one can easily determine the binomial parameters as follows: $u=e^{\sigma \sqrt{\Delta t}}, d=e^{-\sigma \sqrt{\Delta t}}$, and $p=\left(e^{(r-q) \Delta t}-d\right) /(u-d)$.

According to the Central Limit Theorem, ${ }^{6}$ the discrete distribution of the asset price under the CRR model will converge to its continuous-time limit (i.e., Black-Scholes model). In other words, as $\Delta t \rightarrow 0$, the price distribution of the CRR model converges to a lognormal distribution,

$$
\ln S_{T} \stackrel{d}{\rightarrow} N\left(\ln S_{0}+\left(r-q-\frac{\sigma^{2}}{2}\right) T, \sigma \sqrt{T}\right) .
$$

As a result, the option prices calculated by the binomial model will also converge to the Black-Scholes price.

${ }^{6}$ The following condition should be satisfied to apply the Central Limit Theorem:

$$
\frac{p\left|u-e^{(r-q) \Delta t}\right|^{3}+(1-p)\left|d-e^{(r-q) \Delta t}\right|^{3}}{\left[p\left(u-e^{(r-q) \Delta t}\right)^{2}+(1-p)\left(d-e^{(r-q) \Delta t}\right)^{2}\right]^{1.5} \sqrt{n}} \rightarrow 0 \text { as } \Delta t=T / n \rightarrow 0 .
$$




\section{The Binomial Models with Monotonic and Smooth Convergence Property}

Although the CRR model is a well known and widely used model for valuing options, the option prices calculated from it usually converge to the BlackScholes price in a wavy erratic fashion. In order to enhance the accuracy of the binomial option prices, several articles in the recent literature have developed various ways to overcome the wavy erratic problem embedded in the CRR model. Six important binomial models with monotonic and smooth convergence property are discussed and applied in this study. Monotonic convergence is desirable because more time steps do guarantee more accurate prices. Moreover, smooth convergence is also advantageous because the standard Richardson extrapolation can be used to enhance the accuracy.

The first model is the Binomial Black and Scholes (BBS) model proposed by Broadie and Detemple (1996). The BBS model is identical to the CRR model except that at one time step before option maturity the Black-Scholes formula replaces the usual "continuation value." Broadie and Detemple (1996) showed that the option prices obtained from the BBS model converge to the Black-Scholes formula smoothly and monotonically. Thus, they suggested using the Richardson extrapolation to enhance the accuracy.

The second model is the flexible binomial (FB) model of Tian (1999) where a with a "tilt" parameter $(\lambda)$ is introduced to alter the shape and span of the binomial tree. Specifically, the parameters of the FB model are as follows:

$$
u=e^{\sigma \sqrt{\Delta t}+\lambda \sigma^{2} \Delta t}, d=e^{-\sigma \sqrt{\Delta t}+\lambda \sigma^{2} \Delta t}, p=\frac{e^{(r-q) \Delta t}-d}{u-d} .
$$

With a positive tilt parameter, $\lambda>0$, the up movement is larger than the corresponding up move in a standard CRR tree. Consequently, the central nodes depict an upward sloping line. The resulting tree span is thus shifted upward. The exact opposite is true for binomial trees with a negative tilt parameter, $\lambda<0$.

Tian (1999) first proved that his FB model converges to its continuoustime counterparts (i.e., the Black-Scholes model) for any value of the tilt parameter. ${ }^{7}$ He then suggested the way to select a particular tilt parameter that enhances the rate of convergence of binomial prices to their continuous-time limit. This is done by selecting a tilt parameter such that a node in the tree coincides exactly with the strike price at the maturity of the option. ${ }^{8}$ Thus, the formula for determining the tilt parameter is given by:

$$
\lambda=\frac{\ln (X / S)-\left(2 j_{0}-n\right) \sigma \sqrt{\Delta t}}{n \sigma^{2} \Delta t},
$$

\footnotetext{
${ }^{7}$ However, the tilt parameter must satisfy the following inequality in order to have "nonnegative probability": $\left|\lambda-(r-q) / \sigma^{2}\right| \leq 1 / \sigma \sqrt{\Delta t}$.

${ }^{8}$ A similar idea has been applied by Leisen (1998) in his SMO model.
} 
where $j_{0}=\left[\ln (X / S)-n \ln \left(d_{0}\right) / \ln \left(u_{0} / d_{0}\right)\right]$, [.] denotes the closest integer to its argument, $X$ is the strike price, $u_{0}=e^{\sigma \sqrt{\Delta t}}$, and $d_{0}=e^{-\sigma \sqrt{\Delta t}}$. Using the FB model with the above tilt parameter, Tian (1999) showed that monotonic and smooth convergence is possible for pricing standard European and American options, and extrapolation methods are used to enhance the accuracy.

When binomial models are applied to price European and American options, Leisen and Reimer (1996) and Chung and Shih (2007) found that placing the strike price at the center of the tree can improve the efficiency substantially. Thus, we also adjust the FB model in a way that the strike price is placed at the center of the final nodes. This model is called the FB-XPC model in this study. Specifically, the parameters of the FB-XPC model are chosen as follows: ${ }^{9}$

$$
u=e^{\sigma \sqrt{\Delta t}+\lambda \sigma^{2} \Delta t}, d=e^{-\sigma \sqrt{\Delta t}+\lambda \sigma^{2} \Delta t}, p=\frac{e^{(r-q) \Delta t}-d}{u-d} \text { and } \lambda=\ln (X / S) / \sigma^{2} T
$$

The fourth model is the smoothed payoff (SPF) approach of Heston and Zhou (2000). They first showed that the accuracy or rate of convergence of the binomial model depends crucially on the smoothness of the payoff function. Heston and Zhou (2000) then developed an approach to smooth the payoff function. Intuitively, if the payoff function at singular points can be smoothed, the binomial recursion might be more accurate. They defined the smoothed payoff function $G(x)$ as follows:

$$
G(x)=\frac{1}{2 \Delta_{x}} \int_{-\Delta x}^{\Delta x} g(x-y) d y,
$$

where $g(x)$ is the payoff function. This is a rectangular smoothing of $g(x)$. The smoothed function, $G(x)$, can be easily computed analytically for most payoff functions used in practice. For example, the smoothed payoff function of a European put option with a strike price $X$ can be derived as follows:

$$
G\left(S_{T}\right)= \begin{cases}0, & \ln S_{T}-\ln X>\sigma \sqrt{\Delta t} \\ X-S_{T} \frac{e^{\sigma \sqrt{\Delta t}}-e^{-\sigma \sqrt{\Delta t}}}{2 \sigma \sqrt{\Delta t}}, & \ln S_{T}-\ln X<-\sigma \sqrt{\Delta t} \\ \frac{X\left(\sigma \sqrt{\Delta t}-\ln \left(S_{T} / X\right)\right)+S_{T} e^{-\sigma \sqrt{\Delta t}}-X}{2 \sigma \sqrt{\Delta t}}, & -\sigma \sqrt{\Delta t} \leq \ln S_{T}-\ln X \leq \sigma \sqrt{\Delta t}\end{cases}
$$

${ }^{9}$ It is straightforward to verify that the chosen parameters satisfy $S u^{n / 2} d^{n / 2}=X$ and thus the strike price is indeed placed at the center of the final nodes. 
Applying the smoothed payoff function $G(x)$, instead of $g(x)$, to the binomial model yields a rather surprising and interesting result. The binomial option prices of the SPF approach converge at the $O(1 / n)$ rate to its continuous-time limit and this convergence is smooth and monotonic as the number of time steps increases.

The fifth model explored in this study is the generalized CRR (GCRR) model proposed by Chung and Shih (2007). In the GCRR model, the jump sizes and probability of going up are as follows:

$$
u=e^{\lambda \sigma \sqrt{\Delta t}}, d=e^{-\frac{1}{\lambda} \sigma \sqrt{\Delta t}}, \text { and } p=\frac{e^{(r-q) \Delta t}-d}{u-d}
$$

where $\lambda>0$ is a stretch parameter that determines the shape (or spanning) of the binomial tree. The CRR model is obviously a special case of our GCRR model with $\lambda=1$. When $\Delta t \rightarrow 0$, the GCRR binomial option prices also converge to the Black-Scholes formulae for plain vanilla European options.

Generally speaking, the rate of convergence of the GCRR model for pricing options is of order $O(1 / \sqrt{n})$ when $\lambda \neq 1 .{ }^{10}$ This rate of convergence is inferior to other binomial models such as the BBS model and the FB model. Thus, we consider two approaches to adjust the GCRR model. First, we adopt the idea of Tian (1999) by selecting a particular parameter $\lambda$ such that a node in the tree coincides exactly with the strike price at the maturity of the option. Let the initial value of $\lambda$ be one, which represents the CRR model. We can determine the node closest to the strike price $X,\left(n, j_{0}\right)$, by solving the following equation:

$$
\begin{aligned}
S\left(e^{\sigma \sqrt{\Delta t}}\right)^{\eta}\left(e^{-\sigma \sqrt{\Delta t}}\right)^{n-\eta} & =X \\
j_{0} & =[\eta]
\end{aligned}
$$

where [.] denotes the closest integer to its argument. To ensure that node $\left(n, j_{0}\right)$ coincides exactly with the strike price $X$, a new $\lambda$ is selected such that:

$$
S\left(e^{\lambda \sigma \sqrt{\Delta t}}\right)^{j_{0}}\left(e^{-\frac{1}{\lambda} \sigma \sqrt{\Delta t}}\right)^{n-j_{0}}=X
$$

Thus, the formula for determining $\lambda$ is given by:

$$
\lambda=\frac{\ln (X / S)+\sqrt{(\ln (X / S))^{2}+4 j_{0}\left(n-j_{0}\right) \sigma^{2} \Delta t}}{2 j_{0} \sigma \sqrt{\Delta t}} .
$$

This model is essentially a GCRR model with a fine-tuned parameter $\lambda$ closest to one and thus is called GCRR-FT model in this study. ${ }^{11}$

\footnotetext{
${ }^{10}$ Please refer to Theorem 2 of Chung and Shih (2007).

${ }^{11}$ In other words, in GCRR-FT model, the parameter $\lambda$ is chosen to be closest to one such that a node in the tree coincides exactly with the strike price at the maturity of the option. It is straight forward to show that $\lambda$ approaches one as $n$ approaches infinity.
} 
The second adjustment of the GCRR model, suggested by Chung and Shih (2007), is the GCRR-XPC model, where the lattice is set up in a way that the strike price is at the center of the final nodes, to price options. In particular, the binomial option prices of the GCRR-XPC model not only converge at a high order (of order $O(1 / n)$ ) but also converge smoothly and monotonically to the Black-Scholes formula.

In summary, we consider six smooth convergence binomial models, including BBS, SPF, FB, FB-XPC, GCRR-FT, and GCRR-XPC.

\section{Calculating Hedge Ratios with Binomial Models}

Greeks (or hedge ratios) are the sensitivity of the option price with respect to the change of the underlying risk factors. Denote the underlying asset price and the option price at time $i \Delta t$ and state $j$ (i.e. the number of up-movements from time 0) as $S_{i, j}$ and $C_{i, j}$, respectively. Hull (2006) suggested that the estimates of delta and gamma can be obtained as follows:

$$
\begin{gathered}
\hat{\Delta}=\frac{\partial C}{\partial S} \approx\left(C_{1,1}-C_{1,0}\right) /\left(S_{1,1}-S_{1,0}\right) \\
\hat{\Gamma}=\frac{\partial^{2} C}{\partial S^{2}} \approx \frac{\left[\left(C_{2,2}-C_{2,1}\right) /\left(S_{2,2}-S_{2,1}\right)\right]-\left[\left(C_{2,1}-C_{2,0}\right) /\left(S_{2,1}-S_{2,0}\right)\right]}{0.5\left(S_{2,2}-S_{2,0}\right)} .
\end{gathered}
$$

It should be noted that the delta (gamma) estimate obtained from the Hull (2006) method actually represents the delta value at time $\Delta t(2 \Delta t)$ because it is calculated from option prices at time $\Delta t(2 \Delta t)$. To overcome this problem, this study applies the extended tree method of Pelsser and Vorst (1994) to calculate delta and gamma. In the extended binomial tree, we build the binomial tree starting from two time steps prior to time 0. Figure 1 illustrates the extended binomial tree. ${ }^{12}$ The estimates of delta and gamma in the extended tree method can now be obtained as the following:

$$
\begin{gathered}
\hat{\Delta} \approx\left(C_{0,1}-C_{0,-1}\right) /\left(S_{0,1}-S_{0,-1}\right) \\
\hat{\Gamma} \approx \frac{\left[\left(C_{0,1}-C_{0,0}\right) /\left(S_{0,1}-S_{0,0}\right)\right]-\left[\left(C_{0,0}-C_{0,-1}\right) /\left(S_{0,0}-S_{0,-1}\right)\right]}{0.5\left(S_{0,1}-S_{0,-1}\right)} .
\end{gathered}
$$

\footnotetext{
${ }^{12}$ Note that to ensure that the stock price at node $(0,0)$ equals the initial stock price $S_{0}$, i.e. $S_{0,0}=S_{0}$, in our study we choose $S_{-2,-1}=S_{0} /(u d)$ as shown in Figure 1. Therefore, for CRR model, BBS model, and SPF model, $S_{-2,-1}=S_{0}$ because $u d=1$. However, for GCRR-FT model, GCRR-XPC model, FB model, and FB-XPC model, $S_{-2,-1}$ does not equal $S_{0}$ since $u d$ does not equal one.
} 

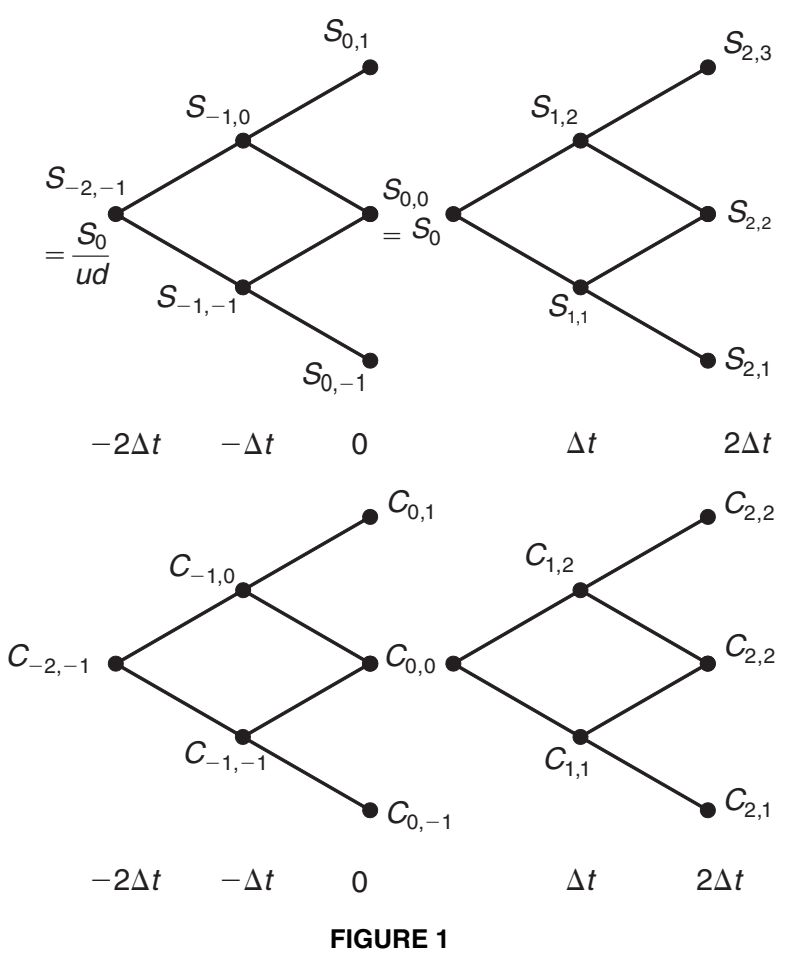

The extended binomial tree.

\section{THE RATE OF CONVERGENCE OF THE BINOMIAL GREEKS AND THE EXTRAPOLATION FORMULA}

When the convergence pattern of the binomial Greeks is monotonic and smooth, one can apply the extrapolation technique to enhance the accuracy. However, the extrapolation formula depends on the rate of convergence of the binomial model. Thus, we will first discuss the rate of convergence of the CRR model and the six binomial models with monotonic and smooth convergence property when they are used to calculate hedge ratios. ${ }^{13}$

\section{The Rate of Convergence of the Binomial Deltas}

In the following, we formally derive the rate of convergence of the CRR, the SPF, and the GCRR-XPC binomial models for computing deltas when the number

\footnotetext{
${ }^{13}$ Note that the rate of convergence of the considered six binomial models for pricing options is of order $O(1 / n)$. Please see Heston and Zhou (2000) and Chung and Shih (2007) for the proofs of the SPF model and the GCRR-XPC model, respectively. However, to the best of our knowledge, the rate of convergence of these six binomial models for computing deltas and gammas is unknown in the literature.
} 


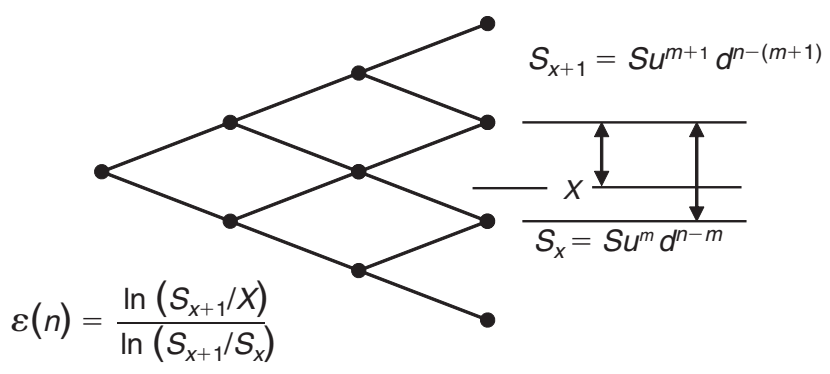

FIGURE 2

Definition of $\varepsilon(n)$.

of time steps increases. ${ }^{14}$ Note that the proof is based on the application using the extended tree method of Pelsser and Vorst (1994). ${ }^{15}$

To show the convergence rate for the CRR model, we need to define a variable, $\varepsilon(n)$, to quantify the position of the final nodes around the strike price. Let $S_{x}=S u^{m} d^{n-m}$ be the closest node at maturity date and smaller than the strike price, i.e., $m$ is the greatest integer which satisfies $S u^{m} d^{n-m} \leq X$. The variable $\varepsilon(n)$ is defined in equation (12) as the logarithmic distance between the strike price and the node above it, normalized with respect to the lattice size $\ln (u / d)$ (see Figure 2), i.e.,

$$
\varepsilon(n)=\frac{\ln \left(S_{x+1} / X\right)}{\ln \left(S_{x+1} / S_{x}\right)}=\frac{\ln \left(S_{x+1} / X\right)}{\ln (u / d)},
$$

where $S_{x+1}=S u^{m+1} d^{n-(m+1)}$ is the price of the final node just above $S_{x}$. Having defined the positioning variable $\varepsilon(n)$, we first present the rate of convergence of the CRR model for calculating deltas in Theorem 1 and then prove this theorem in Appendix Al.

Theorem 1. Let $\hat{\Delta}_{n, C R R}$ be the $n$-period CRR binomial delta of a standard European put option using the extended tree method and $\Delta_{B S}$ is the true delta. Therefore,

$$
\hat{\Delta}_{n, \mathrm{CRR}}=\Delta_{B S}+\frac{e^{-d_{1}^{2} / 2}}{n \sqrt{2 \pi}} f(\varepsilon(n))+O(1 / n)
$$

\footnotetext{
${ }^{14}$ Since the BBS method can be regarded as one way to smooth the payoff function at maturity date, its rate of convergence for computing deltas is the same as that of the SPF method. Moreover, the FB model of Tian (1999) has the same convergence rate as that of the CRR model because both models differ only by an amount of $\lambda \sigma^{2} \Delta t$, which is negligible in comparison to $\sigma \sqrt{\Delta t}$ when $\Delta t$ is small. For simplicity, the proofs for the BBS model, the GCRR-FT model, the FB model, and the FB-XPC model are not shown in this study.

${ }^{15}$ Moreover, the rate of convergence of binomial gammas is of the same order as that of binomial deltas. The derivations for gammas are omitted here and can be obtained from the authors upon request.
} 


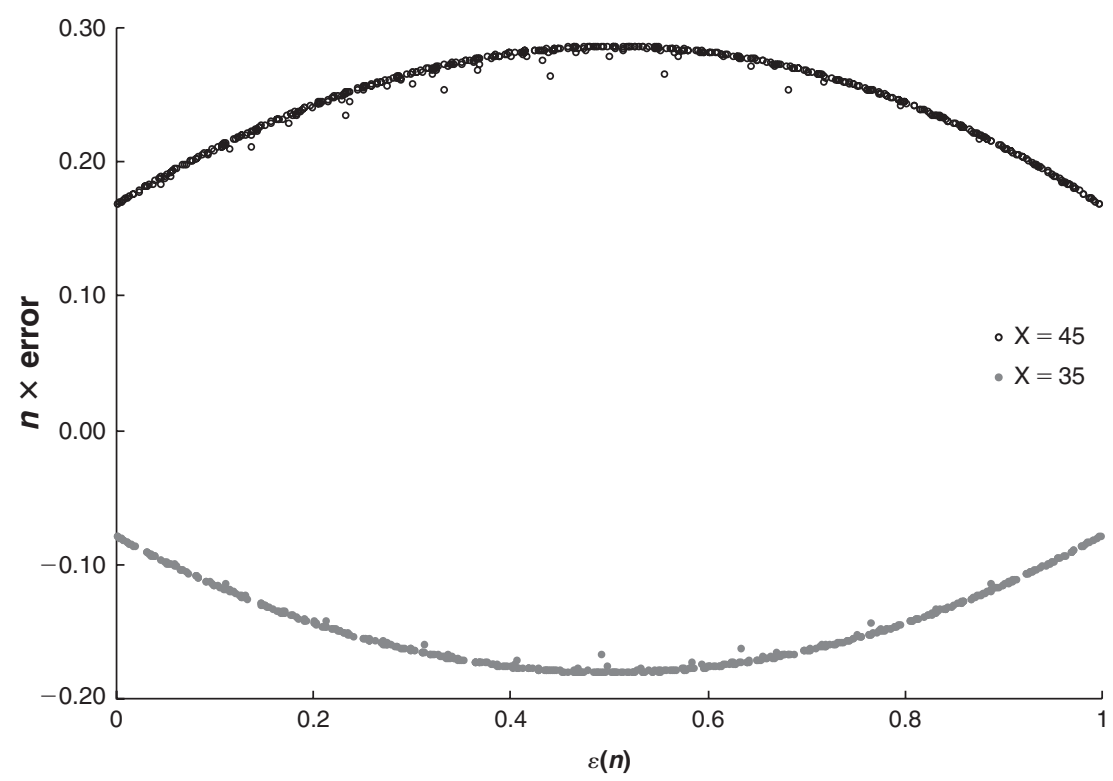

FIGURE 3

A graph of $n \times$ error against $\varepsilon(n)$ for delta estimates of European puts under the CRR model. The parameters used in this figure are: $S=40, \sigma=0.2, r=0.06, T=0.5$, and $q=0$.

where $d_{1}=\frac{\ln (S / X)+\left(r-q+\sigma^{2} / 2\right) T}{\sigma \sqrt{T}}, f(\varepsilon(n))=2 d_{2}\left(-\varepsilon(n)+\varepsilon(n)^{2}\right)$, and $d_{2}=d_{1}-\sigma \sqrt{T}$.

Theorem 1 indicates that, although using the CRR model with an extended tree to calculate delta has the convergence rate of $O(1 / n)$, the convergence pattern may be oscillatory because the relative position of the strike price between two most adjacent nodes (i.e. $\varepsilon(n))$ changes as the number of time steps increases. In addition, if $d_{2}<0\left(d_{2}>0\right)$, the numerical error of delta estimates achieves the highest (lowest) value when $\varepsilon(n)=0.5$. Figure 3 plots the $n \times$ error against $\varepsilon(n)$ for the delta estimates of European puts with strike prices equaling $35\left(d_{2}>0\right)$ and $45\left(d_{2}<0\right)$. The result is as expected that the maximum (minimum) errors occur when $\varepsilon(n)=0.5$ when $d_{2}<0\left(d_{2}>0\right)$.

Our finding echoes the numerical observation of Widdicks, Andricopoulos, Newton, and Duck (WAND, 2002) who found that the pricing error of the CRR model is related to the positioning of the final nodes around the strike price and the error reaches its maximum when $\varepsilon(n)=0.5$ (see their Figure 5 for details). ${ }^{16}$ This study contributes to the literature by proving that the delta error of the CRR model is also related to the positioning of the final

${ }^{16}$ WAND (2002) defined a positioning variable $(\Lambda)$ as the distance between the strike price and the node at or above it, normalized with respect to the lattice size, i.e. $\Lambda(n) \equiv\left(S_{x+1}-X\right) /\left(S_{x+1}-S_{x}\right)$. It is not difficult to verify that $\varepsilon(n)$ and $\Lambda(n)$ is close to each other, especially when $n$ is large. 
nodes around the strike price. Thus, one can follow WAND (2002) to select $n$ to give a constant $\varepsilon(n)$ in the CRR model, to produce monotonic and smooth convergence of delta estimates, and to eradicate the error through extrapolation.

In addition, the rates of convergence of applying extended tree models to compute delta estimates under SPF and GCRR-XPC models are shown in Theorems 2 and 3, respectively. The detailed proofs of these theorems are given in Appendix A2 and A3.

Theorem 2. Let $\hat{\Delta}_{n, S P F}$ be the n-period SPF binomial delta of a standard European put option using the extended tree method and $\Delta_{B S}$ is the true delta. Then,

$$
\hat{\Delta}_{n, S P F}=\Delta_{B S}+O(1 / n) .
$$

Theorem 3. Let $\hat{\Delta}_{n, G C R R-X P C}$ be the n-period GCRR-XPC binomial delta of a standard European put option using the extended tree method and $\Delta_{B S}$ is the true delta. Thus,

$$
\hat{\Delta}_{n, G C R R-X P C}=\Delta_{B S}+O(1 / n) .
$$

\section{The Two-Point Extrapolation Formula}

It is found from Theorems 2 and 3 that the rates of convergence of delta estimates under SPF and GCRR-XPC models are of order $O(1 / n)$. Furthermore, if their convergence patterns are monotonic and smooth, one can apply an extrapolation formula to enhance the accuracy of the delta estimates. In what follows we derive a two-point extrapolation formula when the convergence order is $O(1 / n)$.

Let $e(n)$ be the error of the $n$-step binomial model for computing delta, i.e.:

$$
e(n)=\hat{\Delta}_{n}-\Delta_{B S}
$$

where $\hat{\Delta}_{n}$ is the $n$-step binomial delta and $\Delta_{B S}$ is the Black-Scholes delta. Define the error ratio as:

$$
\rho(n)=e(n / 2) / e(n) .
$$

The error ratio is a measure of the improvements in accuracy as the number of time steps doubles. Given the fact that all the binomial models considered in this study have the convergence order $O(1 / n)$, the error ratios under these models converge to 2 as the number of time steps increases. Thus, the Black-Scholes delta can be approximated using a two-point extrapolation formula as follows:

$$
\tilde{\Delta}_{B S}(n) \approx 2 \hat{\Delta}_{n}-\hat{\Delta}_{n / 2}
$$


It is not difficult to show that the error after applying the extrapolation can be written as:

$$
\tilde{e}(n)=\tilde{\Delta}_{B S}(n)-\Delta_{B S}=(2-\rho(n)) e(n) .
$$

Thus, the error with extrapolation critically depends on the difference between 2 and the error ratio. If the error ratio $\rho(n)$ is within the range of $(1,3)$, the absolute error with extrapolation (i.e., $|\tilde{e}(n)|$ ) is smaller than the absolute error without extrapolation (i.e., $|e(n)|)$. Otherwise, applying the extrapolation method to the binomial deltas will increase rather than decrease the errors.

\section{NUMERICAL RESULTS AND ANALYSIS}

In the following numerical analysis, we will investigate the convergence pattern, the rate of convergence, and the numerical efficiency of various binomial models for computing deltas and gammas.

\section{Convergence Pattern and Convergence Rate of Various Binomial Models}

We first illustrate the convergence patterns of various binomial models considered in this study. Figure 4 shows the convergence patterns of the considered seven binomial models, including the CRR model, the BBS model, the FB model, the FB-XPC model, the SPF method, the GCRR-FT model, and the GCRR-XPC model, for computing delta and gamma of a European put option. The parameters used in Figure 4 are as the following: the asset price is 40, the strike price is 41 , the volatility is 0.3 , the maturity of the option is one month, the risk-free rate is 0.06 , and the dividend yield is 0 . The error is defined as the difference between the binomial estimate and the closed-form solution under the Black-Scholes model. In Figure 4 the delta errors are plotted against the number of even time steps ranging from 10 to $100 .{ }^{17}$ Similarly, Figure 5 shows the convergence patterns of the considered seven models for computing delta and gamma of an American put option with the same parameters as those of Figure 4. The "true" delta and gamma of the American put is calculated using the extended tree of the GCRR-XPC model with a two-point extrapolation $(n=120,000)$.

It is apparent from Figures 4 and 5 that the European and American delta and gamma estimates under the CRR model converge smoothly but not

\footnotetext{
${ }^{17}$ In order to place the strike price exactly in the center node of the final nodes for the FB-XPC model and the GCRR-XPC model, the number of time steps is chosen to be even numbers only.
} 

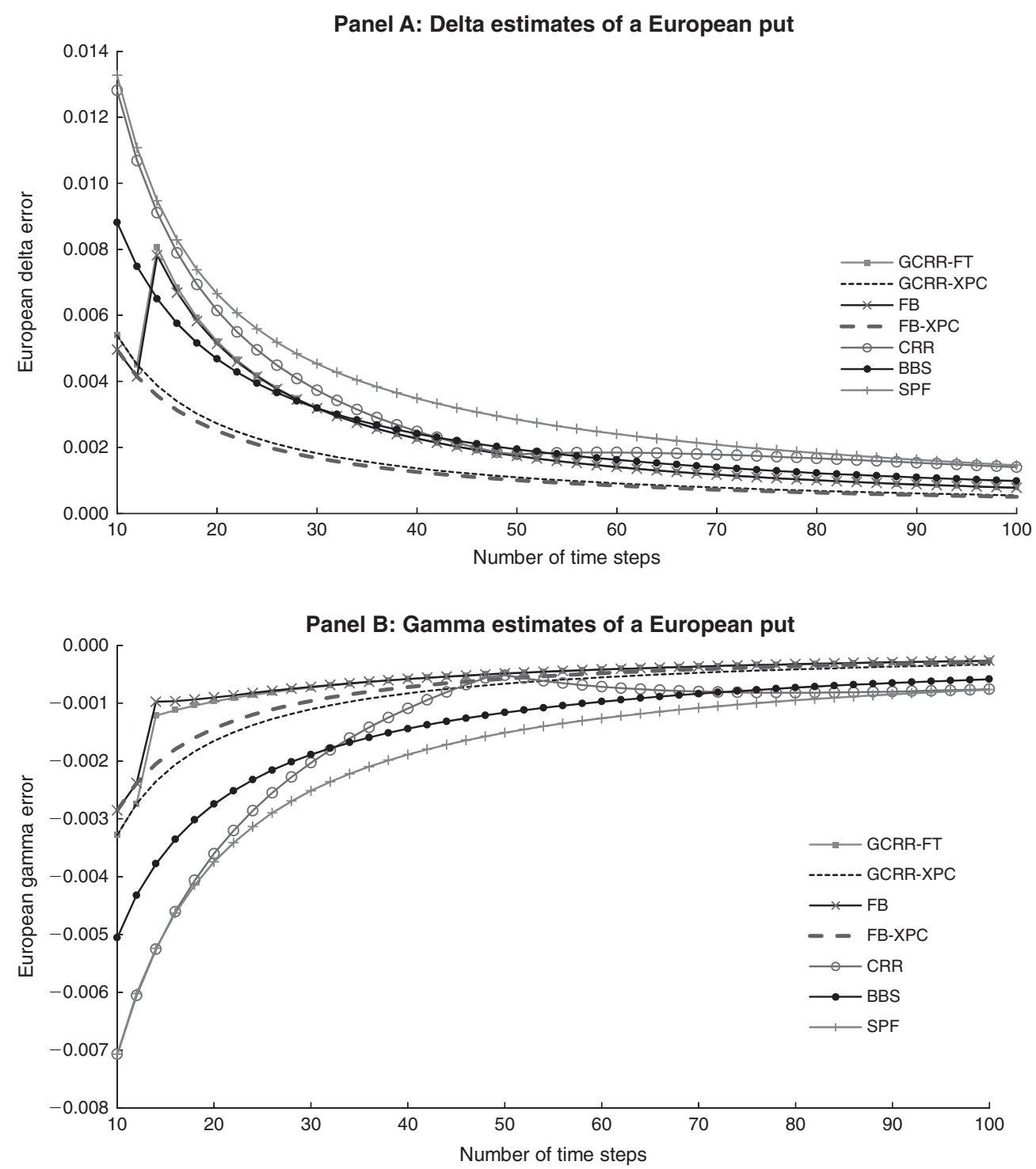

FIGURE 4

Convergence patterns of delta and gamma estimates of a european put. This figure shows the convergence patterns of the GCRR-FT model, the GCRR-XPC model, the FB model, the FB-XPC model, the CRR model, the BBS model, and the SPF model for computing European deltas and gammas. The parameters used in this figure are: $S=40, X=41, \sigma=0.3, r=0.06$, $T=1 / 12$, and $q=0$. 

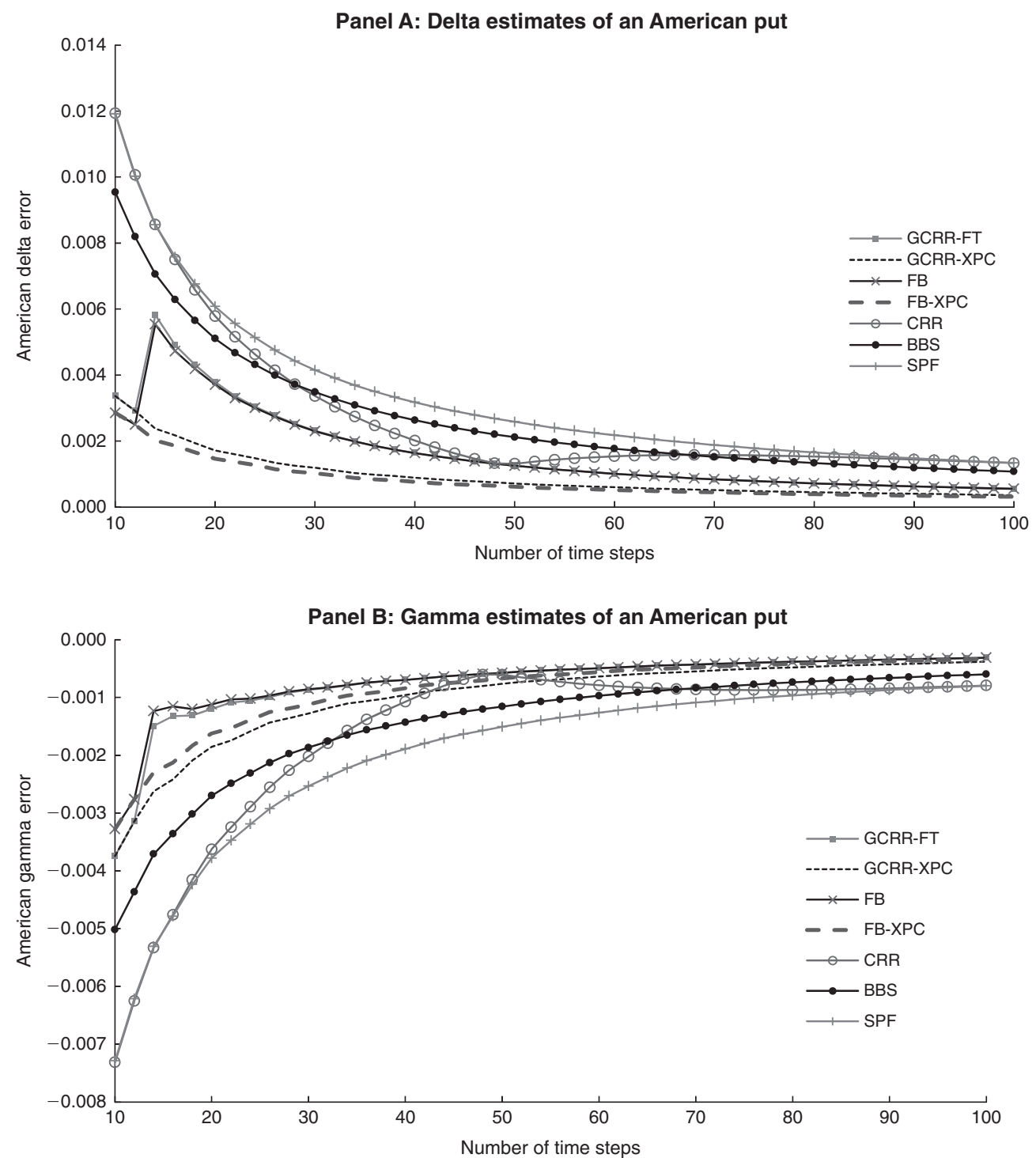

FIGURE 5

Convergence patterns of delta and gamma estimates of an American put. This figure shows the convergence patterns of the GCRR-FT model, the GCRR-XPC model, the FB model, the FB-XPC model, the CRR model, the BBS model, and the SPF model for computing American deltas and gammas. The parameters used in this figure are: $S=40, X=41, \sigma=0.3, r=0.06$, $T=1 / 12$, and $q=0$. 
monotonically to the accurate values. ${ }^{18}$ On the contrary, the delta and gamma estimates under the other six models generally converge smoothly and monotonically (except for the GCRR-FT model and the FB model) ${ }^{19}$ to the accurate values. Therefore, various extrapolation techniques are applicable to these models to enhance the accuracy.

We also analyze the convergence patterns of delta and gamma estimates of European and American put options across different degrees of moneyness. For deep-in-the-money American put options, the probability of early exercise is high and intrinsic value (time value) accounts for a much larger (smaller) fraction of the price of the American put. As intrinsic value is model independent, the considered seven models provide very similar delta and gamma estimates of the American put options. On the contrary, for deep-out-of-the-money put options, the probability of early exercise is low and the early exercise premium on the American put is small. The American put is thus priced more closely to the corresponding European put, and therefore the convergence patterns of European and American put options are quite similar. ${ }^{20}$ For the sake of brevity, these results are not reported here but are available upon request.

Next we numerically investigate the convergence rates of various binomial models for computing European deltas and gammas. The error ratio defined in Equation (17) is reported to measure the improvements in accuracy as the number of time steps doubles. Tables I and II report the error ratios of the BBS model, the FB model, the FB-XPC model, the SPF method, the GCRR-FT model, and the GCRR-XPC model for computing delta and gamma of a European put option, respectively.

It is clear from Tables I and II that the errors of the European delta and gamma estimates under the BBS model, the FB model, the FB-XPC model, the SPF method, the GCRR-FT model, and the GCRR-XPC model are almost exactly halved when the number of time steps doubles, i.e. the error ratio almost equals two. Therefore, the rates of convergence of these models are clearly of order $O(1 / n)$, which are consistent with our theoretical proofs. On the contrary, while the convergence rates of the GCRR-FT and the FB model are of order $O(1 / n)$ for the computation of deltas, their convergence rates for calculating gamma are not stable as the number of time steps increases. ${ }^{21}$

\footnotetext{
${ }^{18}$ Because we plot the figures only using even number of time steps, the convergence pattern of the CRR model generally follows a smooth way. However, when both odd and even numbers of time steps are used, the CRR model converges in a wavy, erratic fashion.

${ }^{19}$ Nevertheless, when the number of time steps increases, the convergence patterns of the GCRR-FT model and the FB model becomes more smooth and monotonica.

${ }^{20}$ We thank the referee for providing the insightful explanations of our results for deep-in-the-money and deep-out-of-the-money put options.

${ }^{21}$ In the unreported numerical results, we find that the errors of the American delta and gamma estimates under the BBS model, the FB model, the FB-XPC model, the SPF method, the GCRR model, and the GCRR-XPC model are also almost exactly halved when the number of time steps doubles.
} 
TABLE I

Delta Estimates and Error Ratios for a European Put Option

\begin{tabular}{|c|c|c|c|c|c|c|}
\hline \multirow[b]{2}{*}{ Time Steps $n$} & \multicolumn{3}{|c|}{$G C R R-F T$} & \multicolumn{3}{|c|}{ GCRR-XPC } \\
\hline & Delta & Error & Error Ratio & Delta & Error & Error Ratio \\
\hline 20 & -0.70052343 & 0.00832001 & - & -0.70116172 & 0.00768172 & - \\
\hline 40 & -0.70463469 & 0.00420875 & 1.9768 & -0.70498601 & 0.00385743 & 1.9914 \\
\hline 80 & -0.70674510 & 0.00209834 & 2.0058 & -0.70691061 & 0.00193283 & 1.9957 \\
\hline 160 & -0.70780289 & 0.00104055 & 2.0166 & -0.70787600 & 0.00096744 & 1.9979 \\
\hline 320 & -0.70832309 & 0.00052035 & 1.9997 & -0.70835946 & 0.00048398 & 1.9989 \\
\hline 640 & -0.70858110 & 0.00026234 & 1.9835 & -0.70860139 & 0.00024205 & 1.9995 \\
\hline 1,280 & -0.70871261 & 0.00013083 & 2.0052 & -0.70872240 & 0.00012104 & 1.9997 \\
\hline 2,560 & -0.70877807 & 0.00006537 & 2.0013 & -0.70878292 & 0.00006052 & 1.9999 \\
\hline \multirow[t]{2}{*}{5,120} & -0.70881073 & 0.00003271 & 1.9984 & -0.70881318 & 0.00003026 & 1.9999 \\
\hline & \multicolumn{3}{|c|}{$F B$} & \multicolumn{3}{|c|}{$F B-X P C$} \\
\hline 20 & -0.70054612 & 0.00829732 & - & -0.70525772 & 0.00358572 & - \\
\hline 40 & -0.70467470 & 0.00416874 & 1.9904 & -0.70703795 & 0.00180549 & 1.9860 \\
\hline 80 & -0.70675074 & 0.00209270 & 1.9920 & -0.70793758 & 0.00090586 & 1.9931 \\
\hline 160 & -0.70780422 & 0.00103922 & 2.0137 & -0.70838974 & 0.00045370 & 1.9966 \\
\hline 320 & -0.70832403 & 0.00051941 & 2.0008 & -0.70861640 & 0.00022704 & 1.9983 \\
\hline 640 & -0.70858135 & 0.00026209 & 1.9818 & -0.70872987 & 0.00011357 & 1.9992 \\
\hline 1,280 & -0.70871262 & 0.00013082 & 2.0033 & -0.70878664 & 0.00005680 & 1.9996 \\
\hline 2,560 & -0.70877807 & 0.00006537 & 2.0013 & -0.70881504 & 0.00002840 & 1.9998 \\
\hline \multirow[t]{2}{*}{5,120} & -0.70881073 & 0.00003271 & 1.9984 & -0.70882924 & 0.00001420 & 1.9999 \\
\hline & \multicolumn{3}{|c|}{$B B S$} & \multicolumn{3}{|c|}{$S P F$} \\
\hline 20 & -0.69711281 & 0.01173063 & - & -0.69514292 & 0.01370052 & - \\
\hline 40 & -0.70284757 & 0.00599587 & 1.9565 & -0.70177061 & 0.00707284 & 1.9371 \\
\hline 80 & -0.70580300 & 0.00304044 & 1.9720 & -0.70526161 & 0.00358183 & 1.9746 \\
\hline 160 & -0.70731402 & 0.00152942 & 1.9880 & -0.70702688 & 0.00181656 & 1.9718 \\
\hline 320 & -0.70807698 & 0.00076646 & 1.9954 & -0.70793373 & 0.00090971 & 1.9968 \\
\hline 640 & -0.70845954 & 0.00038390 & 1.9965 & -0.70838859 & 0.00045485 & 2.0000 \\
\hline 1,280 & -0.70865083 & 0.00019261 & 1.9932 & -0.70861590 & 0.00022754 & 1.9990 \\
\hline 2,560 & -0.70874709 & 0.00009635 & 1.9991 & -0.70872952 & 0.00011392 & 1.9974 \\
\hline 5,120 & -0.70879529 & 0.00004815 & 2.0012 & -0.70878651 & 0.00005693 & 2.0010 \\
\hline True delta & -0.70884344 & & & & & \\
\hline
\end{tabular}

Notes. This table reports European delta estimates, delta errors, and error ratios from the GCRR-FT, GCRR-XPC, FB, FB-XPC, BBS, and SPF models as described in the text by using extended method. The parameters are: the asset price is 40 , the strike price is 45 , the asset price volatility is 0.2 , the maturity of the option is six months, the risk-free rate is 0.06 , and the dividend yield is 0 . The number of time steps starts at 20 and doubles each time subsequently.

Moreover, Tables I and II indicate that the error ratios of the FB-XPC model and the GCRR-XPC model for calculating deltas and gammas also converge monotonically to a constant as $n \rightarrow \infty$. As a result, repeated extrapolation techniques can be used to further reduce the delta and gamma errors of the FB-XPC and the GCRR-XPC model. ${ }^{22}$

\footnotetext{
${ }^{22}$ Within all the binomial models considered in this study, the FB-XPC model and the GCRR-XPC model are the only models that converge so smoothly that one can apply repeated extrapolation techniques. Please see Chang et al. (2007) for the repeated extrapolation formulae and the discussions therein.
} 
TABLE II

Gamma Estimates and Error Ratios for a European Put Option

\begin{tabular}{|c|c|c|c|c|c|c|}
\hline \multirow[b]{2}{*}{ Time Steps $n$} & \multicolumn{3}{|c|}{ GCRR-FT } & \multicolumn{3}{|c|}{ GCRR-XPC } \\
\hline & Gamma & Error & Error Ratio & Gamma & Error & Error Ratio \\
\hline 20 & 0.06087003 & 0.00024585 & - & 0.05909190 & -0.00153227 & - \\
\hline 40 & 0.06080749 & 0.00018332 & 1.3411 & 0.05985084 & -0.00077334 & 1.9814 \\
\hline 80 & 0.06068922 & 0.00006504 & 2.8185 & 0.06023569 & -0.00038848 & 1.9907 \\
\hline 160 & 0.06063049 & 0.00000631 & 10.3095 & 0.06042948 & -0.00019470 & 1.9953 \\
\hline 320 & 0.06062639 & 0.00000221 & 2.8527 & 0.06052671 & -0.00009746 & 1.9977 \\
\hline 640 & 0.06063085 & 0.00000667 & 0.3314 & 0.06057542 & -0.00004876 & 1.9988 \\
\hline 1,280 & 0.06062653 & 0.00000235 & 2.8408 & 0.06059979 & -0.00002439 & 1.9994 \\
\hline 2,560 & 0.06062522 & 0.00000104 & 2.2560 & 0.06061198 & -0.00001220 & 1.9997 \\
\hline \multirow[t]{2}{*}{5,120} & 0.06062477 & 0.00000059 & 1.7705 & 0.06061808 & -0.00000610 & 1.9999 \\
\hline & \multicolumn{3}{|c|}{$F B$} & \multicolumn{3}{|c|}{$F B-X P C$} \\
\hline 20 & 0.06087361 & 0.00024944 & - & 0.05972011 & -0.00090407 & - \\
\hline 40 & 0.06081383 & 0.00018965 & 1.3152 & 0.06017069 & -0.00045349 & 1.9936 \\
\hline 80 & 0.06069011 & 0.00006593 & 2.8764 & 0.06039708 & -0.00022709 & 1.9969 \\
\hline 160 & 0.06063070 & 0.00000652 & 10.1143 & 0.06051055 & -0.00011363 & 1.9985 \\
\hline 320 & 0.06062654 & 0.00000236 & 2.7626 & 0.06056734 & -0.00005684 & 1.9993 \\
\hline 640 & 0.06063089 & 0.00000671 & 0.3515 & 0.06059575 & -0.00002842 & 1.9996 \\
\hline 1,280 & 0.06062653 & 0.00000235 & 2.8572 & 0.06060996 & -0.00001421 & 1.9998 \\
\hline 2,560 & 0.06062522 & 0.00000104 & 2.2564 & 0.06061707 & -0.00000711 & 1.9999 \\
\hline \multirow[t]{2}{*}{5,120} & 0.06062477 & 0.00000059 & 1.7702 & 0.06062062 & -0.00000355 & 2.0000 \\
\hline & \multicolumn{3}{|c|}{$B B S$} & \multicolumn{3}{|c|}{$S P F$} \\
\hline 20 & 0.06010223 & -0.00052194 & - & 0.05979412 & -0.00083006 & - \\
\hline 40 & 0.06037279 & -0.00025139 & 2.0762 & 0.06021492 & -0.00040925 & 2.0282 \\
\hline 80 & 0.06050054 & -0.00012364 & 2.0332 & 0.06042467 & -0.00019951 & 2.0513 \\
\hline 160 & 0.06056230 & -0.00006188 & 1.9981 & 0.06053273 & -0.00009144 & 2.1818 \\
\hline 320 & 0.06059368 & -0.00003050 & 2.0290 & 0.06057755 & -0.00004663 & 1.9610 \\
\hline 640 & 0.06060900 & -0.00001518 & 2.0095 & 0.06060053 & -0.00002365 & 1.9721 \\
\hline 1,280 & 0.06061653 & -0.00000765 & 1.9840 & 0.06061236 & -0.00001181 & 2.0016 \\
\hline 2,560 & 0.06062035 & -0.00000383 & 1.9974 & 0.06061833 & -0.00000585 & 2.0192 \\
\hline 5,120 & 0.06062227 & -0.00000191 & 2.0103 & 0.06062123 & -0.00000295 & 1.9838 \\
\hline True gamma & 0.06062418 & & & & & \\
\hline
\end{tabular}

Notes. This table reports European gamma estimates, gamma errors, and error ratios of the GCRR-FT, GCRR-XPC, FB, FB-XPC, BBS, and SPF models as described in the text by using the extended tree method. The parameters are: the asset price is 40 , the strike price is 45 , the asset price volatility is 0.2 , the maturity of the option is six months, the risk-free rate is 0.06 , and the dividend yield is 0 . The number of time steps starts at 20 and doubles each time subsequently.

\section{Numerical Efficiency of Various Binomial Models for the Computations of Deltas and Gammas}

After confirming the convergence pattern and convergence rate of various binomial models, we next investigate the numerical efficiency of these binomial models for computing deltas and gammas. To have a comprehensive analysis, we choose a large set of options (243 options). The 243 parameter sets are 
drawn from the combinations of $X \in\{35,40,45\}, T \in\{1 / 12,4 / 12,7 / 12\}, r \in$ $\{3 \%, 5 \%, 7 \%\}, q \in\{2 \%, 5 \%, 8 \%\}, \sigma \in\{0.2,0.3,0.4\}$, and $S=40$. We report the results for different numbers of time steps $n \in\{20,40,60,80,100,500$, $1000\}$. The accuracy measure used in this study is the root mean squared (RMS) error, defined as:

$$
\text { RMS error }=\sqrt{\frac{1}{m} \sum_{i=1}^{m} e_{i}^{2}}
$$

where $e_{i}=\hat{c}_{i}-c_{i}$ is the error of the binomial estimate for the $i$ th option, $c_{i}$ is the "true" value, and $\hat{c}_{i}$ is the estimated value from the binomial model. For the European options, the "true" values are estimated from the Black-Scholes formula and for the American options, the "true" values are estimated using the extended tree of the GCRR-XPC model with a two-point extrapolation $(n=120,000)$.

To clarify the role played by Richardson extrapolation, we first compare the numerical efficiency of each model on a raw basis without any extrapolation procedure. Panels A of Tables III and IV report the RMS errors of European delta estimates and American delta estimates respectively for various binomial models. The results indicate that the accuracy of computing deltas is similar for all binomial models considered in this study. Before the extrapolation formula is applied to enhance the accuracy, the FB-XPC method performs slightly better than the other methods from Panels A of Tables III and IV.

Similarly, Panels A of Tables V and VI also suggest that the RMS errors of gamma estimates for various binomial models are of similar magnitude. The GCRR-FT method and the FB method perform similarly and are slightly better than the other methods for computing European and American gamma estimates before the extrapolation technique is used. Moreover, Panels A of Tables III and V also confirm that for European put options, the delta and gamma estimates of all binomial methods compared in this study converge to the Black-Scholes values at the $1 / n$ rate. For example, when $n$ increases from 100 to 1,000 , the RMS errors become approximately one-tenth for each method before the extrapolation technique is applied.

We next compare the numerical efficiency of six smooth convergence models when a two-point extrapolation formula is applied. ${ }^{23}$ According to Tables III and IV, the European and American delta estimates of each method become far more accurate after the extrapolation technique is utilized. For example, from Table III, when $n=1,000$, the RMS error of the FB method for calculating European deltas decreases from 1.00E -4 to $2.94 \mathrm{E}-6$ (i.e. the accuracy improves 34 times) after the extrapolation is applied. In addition, from Table IV, when $n=1,000$, the RMS error of the FB method for calculating

\footnotetext{
${ }^{23}$ We do not apply a two-point extrapolation method to the CRR model since its convergence is oscillatory.
} 
TABLE III

RMS Errors of European Delta Estimates for Various Binomial Models

\begin{tabular}{|c|c|c|c|c|c|c|c|}
\hline Time steps $n$ & 20 & 40 & 60 & 80 & 100 & 500 & 1,000 \\
\hline \multicolumn{8}{|c|}{ Panel A: without extrapolation } \\
\hline CRR & $\begin{array}{c}7.47 \mathrm{E}-03 \\
(0.12)\end{array}$ & $\begin{array}{c}3.94 \mathrm{E}-03 \\
(0.19)\end{array}$ & $\begin{array}{c}2.29 \mathrm{E}-03 \\
(0.27)\end{array}$ & $\begin{array}{c}1.93 \mathrm{E}-03 \\
(0.36)\end{array}$ & $\begin{array}{c}1.49 \mathrm{E}-03 \\
(0.47)\end{array}$ & $\begin{array}{c}3.24 \mathrm{E}-04 \\
(5.58)\end{array}$ & $\begin{array}{c}1.45 \mathrm{E}-04 \\
(21.00)\end{array}$ \\
\hline GCRR-FT & $\begin{array}{c}5.01 \mathrm{E}-03 \\
(0.12)\end{array}$ & $\begin{array}{c}2.51 \mathrm{E}-03 \\
(0.19)\end{array}$ & $\begin{array}{c}1.66 \mathrm{E}-03 \\
(0.27)\end{array}$ & $\begin{array}{c}1.25 \mathrm{E}-03 \\
(0.36)\end{array}$ & $\begin{array}{c}1.01 \mathrm{E}-03 \\
(0.47)\end{array}$ & $\begin{array}{c}2.02 \mathrm{E}-04 \\
(5.59)\end{array}$ & $\begin{array}{c}1.00 \mathrm{E}-04 \\
(21.01)\end{array}$ \\
\hline GCRR-XPC & $\begin{array}{c}5.09 \mathrm{E}-03 \\
(0.14)\end{array}$ & $\begin{array}{c}2.55 \mathrm{E}-03 \\
(0.21)\end{array}$ & $\begin{array}{c}1.70 \mathrm{E}-03 \\
(0.30)\end{array}$ & $\begin{array}{c}1.28 \mathrm{E}-03 \\
(0.40)\end{array}$ & $\begin{array}{c}1.02 \mathrm{E}-03 \\
(0.51)\end{array}$ & $\begin{array}{c}2.05 E-04 \\
(5.75)\end{array}$ & $\begin{array}{c}1.02 \mathrm{E}-04 \\
(21.40)\end{array}$ \\
\hline FB & $\begin{array}{c}4.95 \mathrm{E}-03 \\
(0.12)\end{array}$ & $\begin{array}{c}2.50 \mathrm{E}-03 \\
(0.19)\end{array}$ & $\begin{array}{c}1.66 \mathrm{E}-03 \\
(0.27)\end{array}$ & $\begin{array}{c}1.24 \mathrm{E}-03 \\
(0.36)\end{array}$ & $\begin{array}{c}1.01 \mathrm{E}-03 \\
(0.47)\end{array}$ & $\begin{array}{c}2.02 \mathrm{E}-04 \\
(5.58)\end{array}$ & $\begin{array}{c}1.00 \mathrm{E}-04 \\
(21.00)\end{array}$ \\
\hline FB-XPC & $\begin{array}{c}3.14 \mathrm{E}-03 \\
(0.14)\end{array}$ & $\begin{array}{c}1.57 \mathrm{E}-03 \\
(0.21)\end{array}$ & $\begin{array}{c}1.05 \mathrm{E}-03 \\
(0.30)\end{array}$ & $\begin{array}{c}7.85 \mathrm{E}-04 \\
(0.40)\end{array}$ & $\begin{array}{c}6.28 \mathrm{E}-04 \\
(0.51)\end{array}$ & $\begin{array}{c}1.26 \mathrm{E}-04 \\
(5.74)\end{array}$ & $\begin{array}{c}6.28 \mathrm{E}-05 \\
(21.39)\end{array}$ \\
\hline BBS & $\begin{array}{c}7.31 \mathrm{E}-03 \\
(0.56)\end{array}$ & $\begin{array}{c}3.73 \mathrm{E}-03 \\
(1.00)\end{array}$ & $\begin{array}{c}2.51 \mathrm{E}-03 \\
(1.47)\end{array}$ & $\begin{array}{c}1.89 \mathrm{E}-03 \\
(1.93)\end{array}$ & $\begin{array}{c}1.51 \mathrm{E}-03 \\
(2.42)\end{array}$ & $\begin{array}{c}3.05 E-04 \\
(14.66)\end{array}$ & $\begin{array}{c}1.53 \mathrm{E}-04 \\
(37.28)\end{array}$ \\
\hline SPF & $\begin{array}{c}8.71 \mathrm{E}-03 \\
(0.15)\end{array}$ & $\begin{array}{c}4.45 \mathrm{E}-03 \\
(0.22)\end{array}$ & $\begin{array}{c}2.99 \mathrm{E}-03 \\
(0.32)\end{array}$ & $\begin{array}{c}2.25 \mathrm{E}-03 \\
(0.42)\end{array}$ & $\begin{array}{c}1.80 \mathrm{E}-03 \\
(0.54)\end{array}$ & $\begin{array}{c}3.63 \mathrm{E}-04 \\
(5.91)\end{array}$ & $\begin{array}{c}1.82 \mathrm{E}-04 \\
(21.53)\end{array}$ \\
\hline \multicolumn{8}{|c|}{ Panel B: with extrapolation } \\
\hline GCRR-FT & $\begin{array}{c}9.46 \mathrm{E}-04 \\
(0.16)\end{array}$ & $\begin{array}{c}4.48 \mathrm{E}-04 \\
(0.25)\end{array}$ & $\begin{array}{c}2.32 \mathrm{E}-04 \\
(0.36)\end{array}$ & $\begin{array}{c}1.44 \mathrm{E}-04 \\
(0.49)\end{array}$ & $\begin{array}{c}9.12 \mathrm{E}-05 \\
(0.63)\end{array}$ & $\begin{array}{c}9.54 \mathrm{E}-06 \\
(7.25)\end{array}$ & $\begin{array}{c}2.98 \mathrm{E}-06 \\
(26.49)\end{array}$ \\
\hline GCRR-XPC & $\begin{array}{c}1.55 \mathrm{E}-04 \\
(0.17)\end{array}$ & $\begin{array}{c}4.29 \mathrm{E}-05 \\
(0.28)\end{array}$ & $\begin{array}{c}1.98 \mathrm{E}-05 \\
(0.39)\end{array}$ & $\begin{array}{c}1.14 \mathrm{E}-05 \\
(0.53)\end{array}$ & $\begin{array}{c}7.38 \mathrm{E}-06 \\
(0.69)\end{array}$ & $\begin{array}{c}3.08 \mathrm{E}-07 \\
(7.47)\end{array}$ & $\begin{array}{c}7.73 \mathrm{E}-08 \\
(26.97)\end{array}$ \\
\hline FB & $\begin{array}{c}9.31 \mathrm{E}-04 \\
(0.16)\end{array}$ & $\begin{array}{c}4.36 \mathrm{E}-04 \\
(0.25)\end{array}$ & $\begin{array}{c}2.43 E-04 \\
(0.36)\end{array}$ & $\begin{array}{c}1.40 \mathrm{E}-04 \\
(0.49)\end{array}$ & $\begin{array}{c}9.08 \mathrm{E}-05 \\
(0.63)\end{array}$ & $\begin{array}{c}9.56 \mathrm{E}-06 \\
(7.24)\end{array}$ & $\begin{array}{c}2.94 \mathrm{E}-06 \\
(26.48)\end{array}$ \\
\hline FB-XPC & $\begin{array}{c}2.20 \mathrm{E}-04 \\
(0.17)\end{array}$ & $\begin{array}{l}5.25 \mathrm{E}-05 \\
\quad(0.28)\end{array}$ & $\begin{array}{c}2.30 \mathrm{E}-05 \\
(0.39)\end{array}$ & $\begin{array}{c}1.29 \mathrm{E}-05 \\
(0.53)\end{array}$ & $\begin{array}{c}8.20 \mathrm{E}-06 \\
(0.69)\end{array}$ & $\begin{array}{c}3.24 \mathrm{E}-07 \\
(7.46)\end{array}$ & $\begin{array}{c}8.08 \mathrm{E}-08 \\
(26.96)\end{array}$ \\
\hline BBS & $\begin{array}{c}6.17 \mathrm{E}-04 \\
(0.83)\end{array}$ & $\begin{array}{c}1.71 \mathrm{E}-04 \\
(1.49)\end{array}$ & $\begin{array}{c}8.20 \mathrm{E}-05 \\
(2.16)\end{array}$ & $\begin{array}{c}4.56 \mathrm{E}-05 \\
(2.84)\end{array}$ & $\begin{array}{c}3.06 \mathrm{E}-05 \\
(3.54)\end{array}$ & $\begin{array}{c}1.01 \mathrm{E}-06 \\
(20.96)\end{array}$ & $\begin{array}{c}7.68 \mathrm{E}-07 \\
(51.74)\end{array}$ \\
\hline SPF & $\begin{array}{c}9.22 \mathrm{E}-04 \\
(0.18)\end{array}$ & $\begin{array}{c}2.41 \mathrm{E}-04 \\
(0.29)\end{array}$ & $\begin{array}{c}1.06 \mathrm{E}-04 \\
(0.40)\end{array}$ & $\begin{array}{c}6.70 \mathrm{E}-05 \\
(0.54)\end{array}$ & $\begin{array}{c}4.05 E-05 \\
(0.70)\end{array}$ & $\begin{array}{c}2.19 \mathrm{E}-06 \\
(7.52)\end{array}$ & $\begin{array}{c}9.22 \mathrm{E}-07 \\
(27.27)\end{array}$ \\
\hline
\end{tabular}

Notes. This table reports the RMS errors of European delta estimates under the GCRR-FT, GCRR-XPC, FB, FB-XPC, BBS, and SPF models without- and with-extrapolation, respectively. The 243 parameter sets are drawn from the combinations of $X \in\{35,40,45\}$, $T \in\{1 / 12,4 / 12,7 / 12\}, r \in\{3 \%, 5 \%, 7 \%\}, q \in\{2 \%, 5 \%, 8 \%\}, \sigma \in\{0.2,0.3,0.4\}$, and $S=40$. RMS errors and computational times averaged over 243 different sets of parameters are reported. The CPU time (in seconds) required to value 243 deltas is based on the running time on a Pentium 4 2.8-GHz PC and is given in parentheses.

American deltas decreases from $9.47 \mathrm{E}-05$ to $4.35 \mathrm{E}-06$ (i.e. the accuracy improves 22 times) after the extrapolation is applied.

Although FB-XPC is the best method for calculating European deltas without extrapolation from Panel A of Table III, GCRR-XPC method with extrapolation improves the most (e.g. when $n=1,000$, the accuracy improves 1,320 times!). Among all binomial methods, the GCRR-XPC and the FB-XPC models with extrapolation perform similarly and are the best two methods for computing European and American delta estimates.

Tables V and VI show the RMS errors of gamma estimates of each method for European and American put options, respectively. From Table V, it is evident that the FB and the GCRR-FT methods perform slightly better than 
TABLE IV

RMS Errors of American Delta Estimates for Various Binomial Models

\begin{tabular}{|c|c|c|c|c|c|c|c|}
\hline Time Steps $n$ & 20 & 40 & 60 & 80 & 100 & 500 & 1,000 \\
\hline \multicolumn{8}{|c|}{ Panel A: without extrapolation } \\
\hline CRR & $\begin{array}{c}7.28 \mathrm{E}-03 \\
(0.20)\end{array}$ & $\begin{array}{c}3.86 \mathrm{E}-03 \\
(0.34)\end{array}$ & $\begin{array}{c}2.22 \mathrm{E}-03 \\
(0.50)\end{array}$ & $\begin{array}{c}1.90 \mathrm{E}-03 \\
(0.69)\end{array}$ & $\begin{array}{c}1.45 \mathrm{E}-03 \\
(0.92)\end{array}$ & $\begin{array}{c}3.19 \mathrm{E}-04 \\
(11.81)\end{array}$ & $\begin{array}{c}1.41 \mathrm{E}-04 \\
(45.62)\end{array}$ \\
\hline GCRR-FT & $\begin{array}{c}4.72 \mathrm{E}-03 \\
(0.20)\end{array}$ & $\begin{array}{c}2.37 \mathrm{E}-03 \\
(0.34)\end{array}$ & $\begin{array}{c}1.56 \mathrm{E}-03 \\
(0.50)\end{array}$ & $\begin{array}{c}1.18 \mathrm{E}-03 \\
(0.69)\end{array}$ & $\begin{array}{c}9.48 \mathrm{E}-04 \\
(0.92)\end{array}$ & $\begin{array}{c}1.90 \mathrm{E}-04 \\
(11.81)\end{array}$ & $\begin{array}{c}9.47 \mathrm{E}-05 \\
(45.63)\end{array}$ \\
\hline GCRR-XPC & $\begin{array}{c}4.98 \mathrm{E}-03 \\
(0.22)\end{array}$ & $\begin{array}{c}2.49 \mathrm{E}-03 \\
(0.36)\end{array}$ & $\begin{array}{c}1.66 \mathrm{E}-03 \\
(0.53)\end{array}$ & $\begin{array}{c}1.25 \mathrm{E}-03 \\
(0.73)\end{array}$ & $\begin{array}{c}9.99 \mathrm{E}-04 \\
(0.96)\end{array}$ & $\begin{array}{c}2.00 \mathrm{E}-04 \\
(11.98)\end{array}$ & $\begin{array}{c}1.00 E-04 \\
(46.02)\end{array}$ \\
\hline FB & $\begin{array}{c}4.65 E-03 \\
(0.20)\end{array}$ & $\begin{array}{c}2.35 \mathrm{E}-03 \\
(0.34)\end{array}$ & $\begin{array}{c}1.56 \mathrm{E}-03 \\
(0.50)\end{array}$ & $\begin{array}{c}1.17 \mathrm{E}-03 \\
(0.69)\end{array}$ & $\begin{array}{c}9.46 \mathrm{E}-04 \\
(0.92)\end{array}$ & $\begin{array}{c}1.90 \mathrm{E}-04 \\
(11.81)\end{array}$ & $\begin{array}{c}9.47 \mathrm{E}-05 \\
(45.62)\end{array}$ \\
\hline FB-XPC & $\begin{array}{c}2.86 E-03 \\
(0.22)\end{array}$ & $\begin{array}{c}1.39 \mathrm{E}-03 \\
(0.36)\end{array}$ & $\begin{array}{c}9.27 \mathrm{E}-04 \\
(0.53)\end{array}$ & $\begin{array}{c}6.97 \mathrm{E}-04 \\
(0.73)\end{array}$ & $\begin{array}{c}5.59 \mathrm{E}-04 \\
(0.96)\end{array}$ & $\begin{array}{c}1.11 \mathrm{E}-04 \\
(11.97)\end{array}$ & $\begin{array}{c}5.58 \mathrm{E}-05 \\
(46.01)\end{array}$ \\
\hline BBS & $\begin{array}{c}7.05 E-03 \\
(0.64)\end{array}$ & $\begin{array}{c}3.60 \mathrm{E}-03 \\
(1.15)\end{array}$ & $\begin{array}{c}2.42 \mathrm{E}-03 \\
(1.70)\end{array}$ & $\begin{array}{c}1.83 \mathrm{E}-03 \\
(2.26)\end{array}$ & $\begin{array}{c}1.46 \mathrm{E}-03 \\
(2.87)\end{array}$ & $\begin{array}{c}2.97 \mathrm{E}-04 \\
(20.89)\end{array}$ & $\begin{array}{c}1.49 \mathrm{E}-04 \\
(61.90)\end{array}$ \\
\hline SPF & $\begin{array}{c}8.39 E-03 \\
(0.23)\end{array}$ & $\begin{array}{c}4.29 \mathrm{E}-03 \\
(0.37)\end{array}$ & $\begin{array}{c}2.89 \mathrm{E}-03 \\
(0.55)\end{array}$ & $\begin{array}{c}2.18 \mathrm{E}-03 \\
(0.75)\end{array}$ & $\begin{array}{c}1.74 \mathrm{E}-03 \\
(0.99)\end{array}$ & $\begin{array}{c}3.53 E-04 \\
(12.14)\end{array}$ & $\begin{array}{c}1.77 E-04 \\
(46.15)\end{array}$ \\
\hline \multicolumn{8}{|c|}{ Panel B: with extrapolation } \\
\hline GCRR-FT & $\begin{array}{c}1.13 E-03 \\
(0.27)\end{array}$ & $\begin{array}{c}5.36 \mathrm{E}-04 \\
(0.44)\end{array}$ & $\begin{array}{c}2.16 \mathrm{E}-04 \\
(0.66)\end{array}$ & $\begin{array}{c}1.44 \mathrm{E}-04 \\
(0.93)\end{array}$ & $\begin{array}{c}9.04 \mathrm{E}-05 \\
(1.21)\end{array}$ & $\begin{array}{c}9.53 E-06 \\
(15.06)\end{array}$ & $\begin{array}{c}4.38 \mathrm{E}-06 \\
(56.25)\end{array}$ \\
\hline GCRR-XPC & $\begin{array}{c}7.26 \mathrm{E}-04 \\
(0.28)\end{array}$ & $\begin{array}{c}2.68 \mathrm{E}-04 \\
(0.47)\end{array}$ & $\begin{array}{c}6.80 \mathrm{E}-05 \\
(0.69)\end{array}$ & $\begin{array}{c}5.76 \mathrm{E}-05 \\
(0.97)\end{array}$ & $\begin{array}{c}3.53 \mathrm{E}-05 \\
(1.27)\end{array}$ & $\begin{array}{c}3.82 \mathrm{E}-06 \\
(15.28)\end{array}$ & $\begin{array}{c}2.06 \mathrm{E}-06 \\
(56.69)\end{array}$ \\
\hline FB & $\begin{array}{c}1.12 \mathrm{E}-03 \\
(0.27)\end{array}$ & $\begin{array}{c}5.22 \mathrm{E}-04 \\
(0.44)\end{array}$ & $\begin{array}{c}2.26 \mathrm{E}-04 \\
(0.66)\end{array}$ & $\begin{array}{c}1.41 \mathrm{E}-04 \\
(0.93)\end{array}$ & $\begin{array}{c}9.11 \mathrm{E}-05 \\
(1.21)\end{array}$ & $\begin{array}{c}9.52 \mathrm{E}-06 \\
(15.05)\end{array}$ & $\begin{array}{c}4.35 E-06 \\
(56.24)\end{array}$ \\
\hline FB-XPC & $\begin{array}{c}1.24 \mathrm{E}-03 \\
(0.28)\end{array}$ & $\begin{array}{c}3.88 \mathrm{E}-04 \\
(0.47)\end{array}$ & $\begin{array}{c}1.23 E-04 \\
(0.69)\end{array}$ & $\begin{array}{c}7.54 \mathrm{E}-05 \\
(0.96)\end{array}$ & $\begin{array}{c}3.78 \mathrm{E}-05 \\
(1.27)\end{array}$ & $\begin{array}{c}3.64 \mathrm{E}-06 \\
(15.27)\end{array}$ & $\begin{array}{c}2.01 \mathrm{E}-06 \\
(56.68)\end{array}$ \\
\hline BBS & $\begin{array}{c}9.17 \mathrm{E}-04 \\
(0.94)\end{array}$ & $\begin{array}{c}3.84 \mathrm{E}-04 \\
(1.68)\end{array}$ & $\begin{array}{c}1.16 \mathrm{E}-04 \\
(2.46)\end{array}$ & $\begin{array}{c}9.41 \mathrm{E}-05 \\
(3.28)\end{array}$ & $\begin{array}{c}4.47 \mathrm{E}-05 \\
(4.12)\end{array}$ & $\begin{array}{c}6.89 \mathrm{E}-06 \\
(28.77)\end{array}$ & $\begin{array}{c}3.29 \mathrm{E}-06 \\
(81.50)\end{array}$ \\
\hline SPF & $\begin{array}{c}1.15 \mathrm{E}-03 \\
(0.29)\end{array}$ & $\begin{array}{c}4.52 \mathrm{E}-04 \\
(0.48)\end{array}$ & $\begin{array}{c}1.45 \mathrm{E}-04 \\
(0.70)\end{array}$ & $\begin{array}{c}1.16 \mathrm{E}-04 \\
(0.98)\end{array}$ & $\begin{array}{c}5.63 \mathrm{E}-05 \\
(1.28)\end{array}$ & $\begin{array}{c}7.04 \mathrm{E}-06 \\
(15.33)\end{array}$ & $\begin{array}{c}3.59 \mathrm{E}-06 \\
(57.03)\end{array}$ \\
\hline
\end{tabular}

Notes. This table reports the RMS errors of American delta estimates under the GCRR-FT, GCRR-XPC, FB, FB-XPC, BBS, and SPF models without- and with-extrapolation, respectively. The 243 parameter sets are drawn from the combinations of $X \in\{35,40$, $45\}, T \in\{1 / 12,4 / 12,7 / 12\}, r \in\{3 \%, 5 \%, 7 \%\}, q \in\{2 \%, 5 \%, 8 \%\}$, and $\sigma \in\{0.2,0.3,0.4\}$ and $S=40$. RMS errors and computational times averaged over 243 different sets of parameters are reported. The CPU time (in seconds) required to value 243 deltas is based on the running time on a Pentium 4 2.8-GHz PC and is given in parentheses.

the other methods without any extrapolation procedure for computing European gammas. However, when a two-point extrapolation is applied, the FB-XPC and the GCRR-XPC methods perform best. As for computing American gammas, Table VI also indicates that the FB and the GCRR-FT methods perform slightly better than the other methods. However, when a two-point extrapolation is applied, GCRR-XPC performs slightly better than FB-XPC followed by GCRR, FB, BBS, and SPF for computing American gammas.

To facilitate a fair comparison of the numerical efficiency of various binomial models for computing deltas, we follow Broadie and Detemple (1996) to conduct the speed-accuracy trade-off analysis. Computation speed is measured 
TABLE V

RMS Errors of European Gamma Estimates for Various Binomial Models

\begin{tabular}{|c|c|c|c|c|c|c|c|}
\hline Time steps $n$ & 20 & 40 & 60 & 80 & 100 & 500 & 1,000 \\
\hline \multicolumn{8}{|c|}{ Panel A: without extrapolation } \\
\hline CRR & $\begin{array}{c}9.90 \mathrm{E}-04 \\
(0.12)\end{array}$ & $\begin{array}{c}5.14 \mathrm{E}-04 \\
(0.19)\end{array}$ & $\begin{array}{c}2.99 \mathrm{E}-04 \\
(0.27)\end{array}$ & $\begin{array}{c}2.30 \mathrm{E}-04 \\
(0.36)\end{array}$ & $\begin{array}{c}1.96 \mathrm{E}-04 \\
(0.47)\end{array}$ & $\begin{array}{c}3.91 \mathrm{E}-05 \\
(5.58)\end{array}$ & $\begin{array}{c}2.02 \mathrm{E}-05 \\
(21.00)\end{array}$ \\
\hline GCRR-FT & $\begin{array}{c}7.41 \mathrm{E}-04 \\
(0.12)\end{array}$ & $\begin{array}{c}3.70 \mathrm{E}-04 \\
(0.19)\end{array}$ & $\begin{array}{c}2.42 \mathrm{E}-04 \\
(0.27)\end{array}$ & $\begin{array}{c}1.87 \mathrm{E}-04 \\
(0.36)\end{array}$ & $\begin{array}{c}1.48 \mathrm{E}-04 \\
(0.47)\end{array}$ & $\begin{array}{c}2.93 \mathrm{E}-05 \\
(5.59)\end{array}$ & $\begin{array}{c}1.47 \mathrm{E}-05 \\
(21.01)\end{array}$ \\
\hline GCRR-XPC & $\begin{array}{c}1.11 \mathrm{E}-03 \\
(0.14)\end{array}$ & $\begin{array}{c}5.66 \mathrm{E}-04 \\
(0.21)\end{array}$ & $\begin{array}{c}3.80 \mathrm{E}-04 \\
(0.30)\end{array}$ & $\begin{array}{c}2.86 \mathrm{E}-04 \\
(0.40)\end{array}$ & $\begin{array}{c}2.29 \mathrm{E}-04 \\
(0.51)\end{array}$ & $\begin{array}{c}4.62 \mathrm{E}-05 \\
\quad(5.75)\end{array}$ & $\begin{array}{c}2.31 \mathrm{E}-05 \\
(21.40)\end{array}$ \\
\hline FB & $\begin{array}{c}7.38 \mathrm{E}-04 \\
(0.12)\end{array}$ & $\begin{array}{c}3.69 \mathrm{E}-04 \\
(0.19)\end{array}$ & $\begin{array}{c}2.42 \mathrm{E}-04 \\
(0.27)\end{array}$ & $\begin{array}{c}1.86 \mathrm{E}-04 \\
(0.36)\end{array}$ & $\begin{array}{c}1.48 \mathrm{E}-04 \\
(0.47)\end{array}$ & $\begin{array}{c}2.93 \mathrm{E}-05 \\
(5.58)\end{array}$ & $\begin{array}{c}1.47 \mathrm{E}-05 \\
(21.00)\end{array}$ \\
\hline FB-XPC & $\begin{array}{c}1.76 \mathrm{E}-03 \\
(0.14)\end{array}$ & $\begin{array}{c}8.77 \mathrm{E}-04 \\
(0.21)\end{array}$ & $\begin{array}{c}5.84 \mathrm{E}-04 \\
(0.30)\end{array}$ & $\begin{array}{c}4.38 \mathrm{E}-04 \\
(0.40)\end{array}$ & $\begin{array}{c}3.50 \mathrm{E}-04 \\
(0.51)\end{array}$ & $\begin{array}{c}7.00 \mathrm{E}-05 \\
(5.74)\end{array}$ & $\begin{array}{c}3.50 \mathrm{E}-05 \\
(21.39)\end{array}$ \\
\hline BBS & $\begin{array}{c}1.56 \mathrm{E}-03 \\
(0.56)\end{array}$ & $\begin{array}{c}8.03 E-04 \\
(1.00)\end{array}$ & $\begin{array}{c}5.41 \mathrm{E}-04 \\
(1.47)\end{array}$ & $\begin{array}{c}4.08 \mathrm{E}-04 \\
(1.93)\end{array}$ & $\begin{array}{c}3.27 \mathrm{E}-04 \\
(2.42)\end{array}$ & $\begin{array}{c}6.61 \mathrm{E}-05 \\
(14.66)\end{array}$ & $\begin{array}{c}3.31 \mathrm{E}-05 \\
(37.28)\end{array}$ \\
\hline SPF & $\begin{array}{c}1.98 \mathrm{E}-03 \\
(0.15)\end{array}$ & $\begin{array}{c}1.02 \mathrm{E}-03 \\
(0.22)\end{array}$ & $\begin{array}{c}6.90 \mathrm{E}-04 \\
(0.32)\end{array}$ & $\begin{array}{c}5.20 \mathrm{E}-04 \\
(0.42)\end{array}$ & $\begin{array}{c}4.17 \mathrm{E}-04 \\
(0.54)\end{array}$ & $\begin{array}{c}8.44 \mathrm{E}-05 \\
(5.91)\end{array}$ & $\begin{array}{c}4.23 \mathrm{E}-05 \\
(21.53)\end{array}$ \\
\hline \multicolumn{8}{|c|}{ Panel B: with extrapolation } \\
\hline GCRR-FT & $\begin{array}{c}5.26 \mathrm{E}-04 \\
(0.16)\end{array}$ & $\begin{array}{c}1.57 \mathrm{E}-04 \\
(0.25)\end{array}$ & $\begin{array}{c}6.45 \mathrm{E}-05 \\
(0.36)\end{array}$ & $\begin{array}{c}5.93 E-05 \\
(0.49)\end{array}$ & $\begin{array}{c}3.38 \mathrm{E}-05 \\
(0.63)\end{array}$ & $\begin{array}{c}3.32 \mathrm{E}-06 \\
(7.25)\end{array}$ & $\begin{array}{c}1.25 \mathrm{E}-06 \\
(26.49)\end{array}$ \\
\hline GCRR-XPC & $\begin{array}{c}1.30 \mathrm{E}-04 \\
(0.17)\end{array}$ & $\begin{array}{c}3.67 \mathrm{E}-05 \\
(0.28)\end{array}$ & $\begin{array}{c}1.70 \mathrm{E}-05 \\
(0.39)\end{array}$ & $\begin{array}{c}9.76 \mathrm{E}-06 \\
(0.53)\end{array}$ & $\begin{array}{c}6.32 \mathrm{E}-06 \\
(0.69)\end{array}$ & $\begin{array}{c}2.63 \mathrm{E}-07 \\
(7.47)\end{array}$ & $\begin{array}{c}6.62 \mathrm{E}-08 \\
(26.97)\end{array}$ \\
\hline FB & $\begin{array}{c}5.38 \mathrm{E}-04 \\
(0.16)\end{array}$ & $\begin{array}{c}1.63 \mathrm{E}-04 \\
(0.25)\end{array}$ & $\begin{array}{c}6.49 \mathrm{E}-05 \\
(0.36)\end{array}$ & $\begin{array}{c}5.89 \mathrm{E}-05 \\
(0.49)\end{array}$ & $\begin{array}{c}3.43 E-05 \\
(0.63)\end{array}$ & $\begin{array}{c}3.31 \mathrm{E}-05 \\
(7.24)\end{array}$ & $\begin{array}{c}1.26 \mathrm{E}-06 \\
(26.48)\end{array}$ \\
\hline FB-XPC & $\begin{array}{c}8.77 \mathrm{E}-05 \\
(0.17)\end{array}$ & $\begin{array}{c}1.62 \mathrm{E}-05 \\
(0.28)\end{array}$ & $\begin{array}{c}6.70 \mathrm{E}-06 \\
(0.39)\end{array}$ & $\begin{array}{c}3.65 \mathrm{E}-06 \\
(0.53)\end{array}$ & $\begin{array}{c}2.30 \mathrm{E}-06 \\
(0.69)\end{array}$ & $\begin{array}{c}8.77 \mathrm{E}-08 \\
(7.46)\end{array}$ & $\begin{array}{c}2.18 \mathrm{E}-08 \\
(26.96)\end{array}$ \\
\hline BBS & $\begin{array}{c}1.80 \mathrm{E}-04 \\
(0.83)\end{array}$ & $\begin{array}{c}5.12 \mathrm{E}-05 \\
(1.49)\end{array}$ & $\begin{array}{c}2.35 \mathrm{E}-05 \\
(2.16)\end{array}$ & $\begin{array}{c}1.40 \mathrm{E}-05 \\
(2.84)\end{array}$ & $\begin{array}{c}8.92 \mathrm{E}-06 \\
(3.54)\end{array}$ & $\begin{array}{c}3.99 \mathrm{E}-07 \\
(20.96)\end{array}$ & $\begin{array}{c}1.17 \mathrm{E}-07 \\
(51.74)\end{array}$ \\
\hline SPF & $\begin{array}{c}2.93 \mathrm{E}-04 \\
(0.18)\end{array}$ & $\begin{array}{c}8.07 \mathrm{E}-05 \\
(0.29)\end{array}$ & $\begin{array}{c}3.94 \mathrm{E}-05 \\
(0.40)\end{array}$ & $\begin{array}{c}2.28 \mathrm{E}-05 \\
(0.54)\end{array}$ & $\begin{array}{c}1.48 \mathrm{E}-05 \\
(0.70)\end{array}$ & $\begin{array}{c}9.93 \mathrm{E}-07 \\
(7.52)\end{array}$ & $\begin{array}{c}3.32 \mathrm{E}-07 \\
(27.27)\end{array}$ \\
\hline
\end{tabular}

Notes. This table reports the RMS errors of European gamma estimates under the GCRR-FT, GCRR-XPC, FB, FB-XPC, BBS, and SPF models without- and with-extrapolation, respectively. The 243 parameter sets are drawn from the combinations of $X \in\{35,40$, $45\}, T \in\{1 / 12,4 / 12,7 / 12\}, r \in\{3 \%, 5 \%, 7 \%\}, q \in\{2 \%, 5 \%, 8 \%\}$, and $\sigma \in\{0.2,0.3,0.4\}$ and $S=40$. RMS errors and computational times averaged over 243 different sets of parameters are reported. The CPU time (in seconds) required to value 243 deltas is based on the running time on a Pentium 4 2.8-GHz PC and is given in parentheses.

in option prices calculated per second and is based on the running time on a Pentium 4 2.8-GHz PC. The accuracy measure is the RMS error averaged over the 243 options used in Table III. The overall results are given in Figure 6. Because of the extreme differences in speed and accuracy, the results are shown on a $\log -\log$ scale. Note that preferred methods are in the upper-left corner. The results of Figure 6 are similar to those of Table III. For example, Figure 6 also suggests that the FB-XPC and GCRR-XPC models with a twopoint extrapolation dominate all the other methods for computing European deltas. In summary, the results suggest that placing the strike price at the center of the tree can enhance the accuracy. Similar results are found by 
TABLE VI

RMS Errors of American Gamma Estimates for Various Binomial Models

\begin{tabular}{|c|c|c|c|c|c|c|c|}
\hline Time Steps $n$ & 20 & 40 & 60 & 80 & 100 & 500 & 1,000 \\
\hline \multicolumn{8}{|c|}{ Panel A: without extrapolation } \\
\hline CRR & $\begin{array}{c}9.60 \mathrm{E}-04 \\
(0.20)\end{array}$ & $\begin{array}{c}5.05 E-04 \\
(0.34)\end{array}$ & $\begin{array}{c}3.00 \mathrm{E}-04 \\
(0.50)\end{array}$ & $\begin{array}{c}2.32 \mathrm{E}-04 \\
(0.69)\end{array}$ & $\begin{array}{c}1.94 \mathrm{E}-04 \\
(0.92)\end{array}$ & $\begin{array}{c}3.86 E-05 \\
(11.81)\end{array}$ & $\begin{array}{c}2.00 \mathrm{E}-05 \\
(45.62)\end{array}$ \\
\hline GCRR-FT & $\begin{array}{c}8.02 E-04 \\
(0.20)\end{array}$ & $\begin{array}{c}3.78 E-04 \\
(0.34)\end{array}$ & $\begin{array}{c}2.47 \mathrm{E}-04 \\
(0.50)\end{array}$ & $\begin{array}{c}1.89 \mathrm{E}-04 \\
(0.69)\end{array}$ & $\begin{array}{c}1.52 \mathrm{E}-04 \\
(0.92)\end{array}$ & $\begin{array}{c}2.97 E-05 \\
(11.81)\end{array}$ & $\begin{array}{c}1.51 \mathrm{E}-05 \\
(45.63)\end{array}$ \\
\hline GCRR-XPC & $\begin{array}{c}1.12 \mathrm{E}-03 \\
(0.22)\end{array}$ & $\begin{array}{c}5.61 \mathrm{E}-04 \\
(0.36)\end{array}$ & $\begin{array}{c}3.76 \mathrm{E}-04 \\
(0.53)\end{array}$ & $\begin{array}{c}2.83 E-04 \\
(0.73)\end{array}$ & $\begin{array}{c}2.25 \mathrm{E}-04 \\
(0.96)\end{array}$ & $\begin{array}{c}4.55 \mathrm{E}-05 \\
(11.98)\end{array}$ & $\begin{array}{c}2.26 \mathrm{E}-05 \\
(46.02)\end{array}$ \\
\hline FB & $\begin{array}{c}8.00 E-04 \\
(0.20)\end{array}$ & $\begin{array}{c}3.77 \mathrm{E}-04 \\
(0.34)\end{array}$ & $\begin{array}{c}2.47 \mathrm{E}-04 \\
(0.50)\end{array}$ & $\begin{array}{c}1.89 \mathrm{E}-04 \\
(0.69)\end{array}$ & $\begin{array}{c}1.52 \mathrm{E}-04 \\
(0.92)\end{array}$ & $\begin{array}{c}2.97 \mathrm{E}-05 \\
(11.81)\end{array}$ & $\begin{array}{c}1.51 \mathrm{E}-05 \\
(45.62)\end{array}$ \\
\hline FB-XPC & $\begin{array}{c}2.36 \mathrm{E}-03 \\
(0.22)\end{array}$ & $\begin{array}{c}8.30 \mathrm{E}-04 \\
(0.36)\end{array}$ & $\begin{array}{c}5.41 \mathrm{E}-04 \\
(0.53)\end{array}$ & $\begin{array}{c}3.99 \mathrm{E}-04 \\
(0.73)\end{array}$ & $\begin{array}{c}3.19 \mathrm{E}-04 \\
(0.96)\end{array}$ & $\begin{array}{c}6.42 \mathrm{E}-05 \\
(11.97)\end{array}$ & $\begin{array}{c}3.19 \mathrm{E}-05 \\
(46.00)\end{array}$ \\
\hline BBS & $\begin{array}{c}1.53 E-03 \\
(0.64)\end{array}$ & $\begin{array}{c}7.87 \mathrm{E}-04 \\
(1.15)\end{array}$ & $\begin{array}{c}5.32 \mathrm{E}-04 \\
(1.70)\end{array}$ & $\begin{array}{c}4.01 \mathrm{E}-04 \\
(2.26)\end{array}$ & $\begin{array}{c}3.22 \mathrm{E}-04 \\
(2.87)\end{array}$ & $\begin{array}{c}6.53 E-05 \\
(20.89)\end{array}$ & $\begin{array}{c}3.29 \mathrm{E}-05 \\
(61.90)\end{array}$ \\
\hline SPF & $\begin{array}{c}1.94 \mathrm{E}-03 \\
(0.23)\end{array}$ & $\begin{array}{c}1.01 E-03 \\
(0.37)\end{array}$ & $\begin{array}{c}6.81 \mathrm{E}-04 \\
(0.55)\end{array}$ & $\begin{array}{c}5.13 E-04 \\
(0.75)\end{array}$ & $\begin{array}{c}4.11 \mathrm{E}-04 \\
(0.99)\end{array}$ & $\begin{array}{c}8.36 \mathrm{E}-05 \\
(12.14)\end{array}$ & $\begin{array}{c}4.20 E-05 \\
(46.15)\end{array}$ \\
\hline \multicolumn{8}{|c|}{ Panel B: with extrapolation } \\
\hline GCRR-FT & $\begin{array}{c}7.87 \mathrm{E}-04 \\
(0.27)\end{array}$ & $\begin{array}{c}4.19 E-04 \\
(0.44)\end{array}$ & $\begin{array}{c}1.92 \mathrm{E}-04 \\
(0.66)\end{array}$ & $\begin{array}{c}7.88 \mathrm{E}-05 \\
(0.93)\end{array}$ & $\begin{array}{c}6.77 \mathrm{E}-05 \\
(1.21)\end{array}$ & $\begin{array}{c}1.18 \mathrm{E}-05 \\
(15.06)\end{array}$ & $\begin{array}{c}5.97 \mathrm{E}-06 \\
(56.25)\end{array}$ \\
\hline GCRR-XPC & $\begin{array}{c}3.34 \mathrm{E}-04 \\
(0.28)\end{array}$ & $\begin{array}{c}2.36 E-04 \\
(0.47)\end{array}$ & $\begin{array}{c}8.07 \mathrm{E}-05 \\
(0.69)\end{array}$ & $\begin{array}{c}6.23 E-05 \\
(0.97)\end{array}$ & $\begin{array}{c}3.61 \mathrm{E}-05 \\
(1.27)\end{array}$ & $\begin{array}{c}5.67 \mathrm{E}-06 \\
(15.28)\end{array}$ & $\begin{array}{c}2.88 \mathrm{E}-06 \\
(56.69)\end{array}$ \\
\hline FB & $\begin{array}{c}7.98 \mathrm{E}-04 \\
(0.27)\end{array}$ & $\begin{array}{c}4.23 E-04 \\
(0.44)\end{array}$ & $\begin{array}{c}1.94 \mathrm{E}-04 \\
(0.66)\end{array}$ & $\begin{array}{c}7.96 \mathrm{E}-05 \\
(0.93)\end{array}$ & $\begin{array}{c}6.76 \mathrm{E}-05 \\
(1.21)\end{array}$ & $\begin{array}{c}1.18 \mathrm{E}-05 \\
(15.05)\end{array}$ & $\begin{array}{c}5.98 \mathrm{E}-06 \\
(56.24)\end{array}$ \\
\hline FB-XPC & $\begin{array}{c}1.83 E-03 \\
(0.28)\end{array}$ & $\begin{array}{c}3.30 \mathrm{E}-04 \\
(0.47)\end{array}$ & $\begin{array}{c}2.53 \mathrm{E}-04 \\
(0.69)\end{array}$ & $\begin{array}{c}1.40 \mathrm{E}-04 \\
(0.96)\end{array}$ & $\begin{array}{c}8.78 \mathrm{E}-05 \\
(1.27)\end{array}$ & $\begin{array}{c}8.58 \mathrm{E}-06 \\
(15.27)\end{array}$ & $\begin{array}{c}3.45 \mathrm{E}-06 \\
(56.68)\end{array}$ \\
\hline BBS & $\begin{array}{c}5.34 \mathrm{E}-04 \\
(0.94)\end{array}$ & $\begin{array}{c}3.48 \mathrm{E}-04 \\
(1.68)\end{array}$ & $\begin{array}{c}1.78 \mathrm{E}-04 \\
(2.46)\end{array}$ & $\begin{array}{c}4.79 \mathrm{E}-05 \\
(3.28)\end{array}$ & $\begin{array}{c}7.56 \mathrm{E}-05 \\
(4.12)\end{array}$ & $\begin{array}{c}1.29 E-05 \\
(28.77)\end{array}$ & $\begin{array}{c}6.11 \mathrm{E}-06 \\
(81.50)\end{array}$ \\
\hline SPF & $\begin{array}{c}5.51 \mathrm{E}-04 \\
(0.29)\end{array}$ & $\begin{array}{c}3.14 \mathrm{E}-04 \\
(0.48)\end{array}$ & $\begin{array}{c}1.85 \mathrm{E}-04 \\
(0.70)\end{array}$ & $\begin{array}{c}4.49 \mathrm{E}-05 \\
(0.98)\end{array}$ & $\begin{array}{c}7.61 \mathrm{E}-05 \\
(1.28)\end{array}$ & $\begin{array}{c}1.35 \mathrm{E}-05 \\
(15.33)\end{array}$ & $\begin{array}{c}6.39 \mathrm{E}-06 \\
(57.03)\end{array}$ \\
\hline
\end{tabular}

Notes. This table reports the RMS errors of American gamma estimates under the GCRR-FT, GCRR-XPC, FB, FB-XPC, BBS, and SPF models without- and with-extrapolation, respectively. The 243 parameter sets are drawn from the combinations of $X \in\{35,40$, $45\}, T \in\{1 / 12,4 / 12,7 / 12\}, r \in\{3 \%, 5 \%, 7 \%\}, q \in\{2 \%, 5 \%, 8 \%\}$, and $\sigma \in\{0.2,0.3,0.4\}$ and $S=40$. RMS errors and computational times averaged over 243 different sets of parameters are reported. The CPU time (in seconds) required to value 243 deltas is based on the running time on a Pentium 4 2.8-GHz PC and is given in parentheses.

Leisen and Reimer (1996) and Chung and Shih (2007) when binomial models are applied to price options.

It is worth noting that all the smooth convergence models considered in this study are pretty good models for calculating option Greeks. The numerical errors (Tables I and II) are generally quite small for most practical applications. Thus generality and ease of implementation may be more important in choosing the model for a particular application. ${ }^{24}$ For example, the FB model and the GCRR model are flexible to compute prices and Greeks for barrier options, please see Tian (1999) and Chung and Shih (2007), respectively. In terms of

${ }^{24}$ We thank the referee for pointing out this issue. 

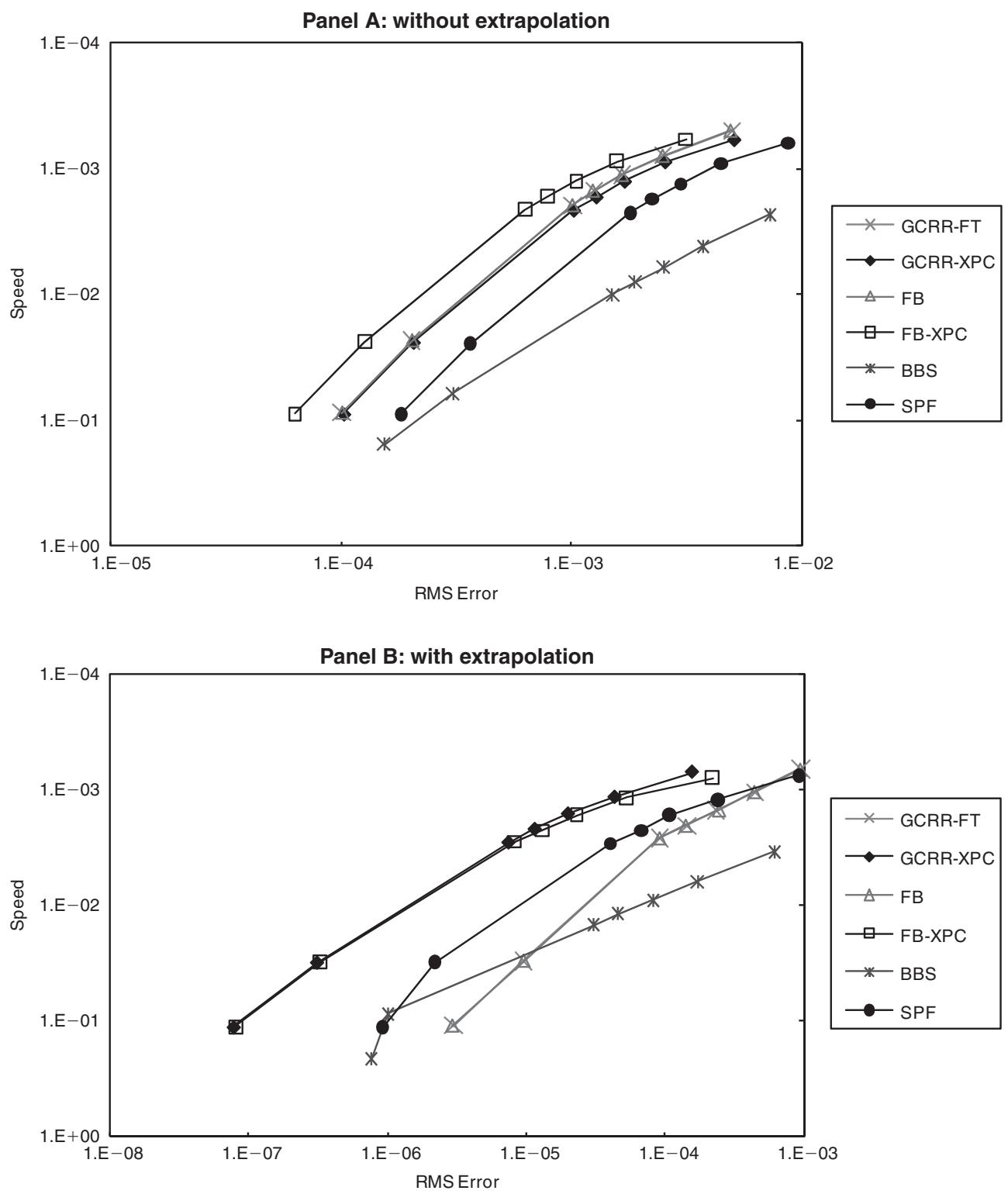

FIGURE 6

Speed-accuracy trade-off analysis of various binomial models for computing European deltas. This figure shows the speed-accuracy trade-off analysis of the six models for calculating deltas of European put options. The results of each binomial model without and with extrapolation are shown in Panels A and B, respectively. Computation speed is measured in option prices calculated per second and is based on the running time on a Pentium $42.8-\mathrm{GHz}$ PC. The accuracy measure is the RMS error averaged over the 243 parameter sets, which are drawn from the combinations of $X \in\{35,40,45\}, T \in\{1 / 12$, $4 / 12,7 / 12\}, r \in\{3 \%, 5 \%, 7 \%\}, q \in\{2 \%, 5 \%, 8 \%\}, \sigma \in\{0.2,0.3,0.4\}$, and $S=40$. GCRR-FT, GCRR$\mathrm{XPC}, \mathrm{FB}, \mathrm{FB}-\mathrm{XPC}, \mathrm{BBS}$, and SPF models are as described in the text. Preferred methods are in the upper-left corner. 
ease of implementation, FB, FB-XPC, GCRR-FT, and GCRR-XPC are better methods than the BBS model because the latter requires extra computer codes and time to compute the Black-Scholes formulae at the time step just before option maturity.

\section{CONCLUSIONS}

This study fills the gap in the literature by showing the convergence patterns and rates of convergence for computing hedge ratios for seven binomial models, including the CRR model, the binomial Black-Scholes (BBS) model of Broadie and Detemple (1996), the flexible binomial model (FB) of Tian (1999), the FB-XPC model, the smoothed payoff (SPF) approach of Heston and Zhou (2000), and two GCRR-type models (GCRR-FT and GCRR-XPC) of Chung and Shih (2007).

The main contributions and results of this study are: (1) we prove that the rates of convergence of these binomial models for computing deltas and gammas are of order $O(1 / n) ;(2)$ the delta estimation error under the CRR model is a quadratic function of the positioning variable $\varepsilon(n)$, which achieves the highest (lowest) value at $\varepsilon(n)=0.5$ when $X>S(X<S)$; (3) we show that binomial Greeks converge to their accurate values smoothly and monotonically (except for the CRR model and the gamma estimates of the FB and the GCRR-FT models) and thus one can enhance their accuracy using the extrapolation technique; (4) the numerical results indicate that the FB-XPC and the GCRR-XPC models are the most efficient methods for computing European and American Greeks when a two-point extrapolation formula is used. This finding suggests that placing the strike price at the center of the final nodes seems to improve the numerical performance substantially.

\section{APPENDIX}

\section{Proof of Theorem 1}

We first prove the rate of convergence of the delta estimates under the CRR model. Substituting $u=e^{\sigma \sqrt{\Delta t}}$ and $d=e^{-\sigma \sqrt{\Delta t}}$ into the definition of $\varepsilon(n)$ (see Figure 2) yields

$$
\begin{gathered}
S u^{m} d^{n-m}=X e^{-2 \sigma \sqrt{\Delta t}(1-\varepsilon(n))} \\
m=\frac{n}{2}+\frac{\ln (X / S)}{2 \sigma \sqrt{\Delta t}}-(1-\varepsilon(n))=\frac{n}{2}+z
\end{gathered}
$$

where $z=\frac{\ln (X / S)}{2 \sigma \sqrt{\Delta t}}-(1-\varepsilon(n))$ and $0<\varepsilon(n) \leq 1$. On the other hand, the risk neutral probability $p$ can be approximated as follows: 


$$
p=\frac{e^{(r-q) \Delta t}-e^{-\sigma \sqrt{\Delta t}}}{e^{\sigma \sqrt{\Delta t}}-e^{-\sigma \sqrt{\Delta t}}}=\frac{1}{2}+b \sqrt{\Delta t}+O(1 / n)
$$

where $b=\left(r-q-0.5 \times \sigma^{2}\right) / 2 \sigma$.

In the extended tree, the European put option values at nodes $S_{0,1}=S u^{2}$ and $S_{0,-1}=S d^{2}$ are, respectively, given by

$$
\begin{gathered}
C_{0,1}=e^{-r T} \sum_{j=0}^{m-1} C_{j}^{n} p^{j}(1-p)^{n-j}\left(X-S u^{2} u^{j} d^{n-j}\right) \\
C_{0,-1}=e^{-r T} \sum_{j=0}^{m+1} C_{j}^{n} p^{j}(1-p)^{n-j}\left(X-S d^{2} u^{j} d^{n-j}\right) .
\end{gathered}
$$

Thus, the delta estimate in the CRR model under the extended tree method is given by $\hat{\Delta}_{n, C R R}=\frac{(A 4)-(A 5)}{S\left(u^{2}-d^{2}\right)}$. We denote $(\mathrm{A} 4)-(\mathrm{A} 5)=A+B+C$, where

$$
\begin{aligned}
& A=-X e^{-r T}\left[C_{m}^{n} p^{m}(1-p)^{n-m}+C_{m+1}^{n} p^{m+1}(1-p)^{n-m-1}\right] \\
& B=-e^{-r T}\left[-C_{m}^{n} p^{m}(1-p)^{n-m} S u^{2} u^{m} d^{n-m}+C_{m+1}^{n} p^{m+1}(1-p)^{n-m-1} S d^{2} u^{m+1} d^{n-m-1}\right] \\
& C=-e^{-r T} \sum_{j=0}^{m} C_{j}^{n} p^{j}(1-p)^{n-j}\left(S u^{2}-S d^{2}\right) u^{j} d^{n-j} .
\end{aligned}
$$

Because

$$
\begin{aligned}
\frac{C}{S\left(u^{2}-d^{2}\right)} & =-e^{-r T} \sum_{j=0}^{m} C_{j}^{n} p^{j}(1-p)^{n-j} u^{j} d^{n-j} \\
& =-e^{-q T} \sum_{j=0}^{m} C_{j}^{n} p^{* j}\left(1-p^{*}\right)^{n-j}
\end{aligned}
$$

according to Chung and Shih $(2007$, p. 518, (16)), we have

$$
\frac{C}{S\left(u^{2}-d^{2}\right)}=-e^{-q T} N\left(-d_{1}+\frac{\varepsilon(n)-0.5}{\sqrt{n p^{*}\left(1-p^{*}\right)}}\right)+O(1 / n)
$$

where $p^{*}=\frac{p u}{e^{(r-q) \Delta t}}$.

Since $C_{m+1}^{n}=C_{m}^{n} \times \frac{n-m}{m+1}$ and $S u^{m} d^{n-m}=X e^{-2 \sigma \sqrt{\Delta t}(1-\varepsilon(n))}$ by (A1), we have

$$
\begin{aligned}
A+B= & X e^{-r T} C_{m}^{n} p^{m}(1-p)^{n-m}\left[u^{2} e^{-2 \sigma \sqrt{\Delta t}(1-\varepsilon(n))}\right. \\
& \left.+\frac{p e^{-2 \sigma \sqrt{\Delta t}(1-\varepsilon(n))}}{1-p} \frac{n-m}{m+1}-1-\frac{p}{1-p} \frac{n-m}{m+1}\right] \\
= & X e^{-r T} C_{m}^{n} p^{m}(1-p)^{n-m} D
\end{aligned}
$$


where

$$
D=u^{2} e^{-2 \sigma \sqrt{\Delta t}(1-\varepsilon(n))}+\frac{p e^{-2 \sigma \sqrt{\Delta t}(1-\varepsilon(n))}}{1-p} \frac{n-m}{m+1}-1-\frac{p}{1-p} \frac{n-m}{m+1}
$$

From (A2) and

$$
\frac{n-m}{m+1}=\frac{1-2 z / n}{1+2(z+1) / n}=\left(1-\frac{2 z}{n}\right)\left[1-\frac{2(z+1)}{n}+\frac{4(z+1)^{2}}{n^{2}}+\ldots\right]
$$

we get

$$
\frac{n-m}{m+1}=1-\frac{2 \ln (X / S)}{n \sigma \sqrt{\Delta t}}+O\left(e_{1}[\varepsilon(n)] / n\right) .
$$

Besides, we have

$$
u^{2} e^{-2 \sigma \sqrt{\Delta t}(1-\varepsilon(n))}-1=2 \sigma \sqrt{\Delta t} \varepsilon(n)+2 \sigma^{2} \Delta t \varepsilon^{2}(n)+O\left(e_{2}[\varepsilon(n)] / n^{1.5}\right)
$$

and by (A3)

$$
\frac{p}{1-p}=1+4 b \sqrt{\Delta t}+O(1 / n)
$$

Therefore, $D$ defined in (A8) can be rewritten as follows:

$$
\begin{aligned}
D= & \left\{1-\frac{2 \ln (X / S)}{n \sigma \sqrt{\Delta t}}+O\left(e_{1}[\varepsilon(n)] / n\right)\right\}[1+4 b \sqrt{\Delta t}+O(1 / n)] \\
& \times\left\{-2 \sigma \sqrt{\Delta t}(1-\varepsilon(n))+2 \sigma^{2} \Delta t(1-\varepsilon(n))^{2}+O\left(e_{3}[\varepsilon(n)] / n^{1.5}\right)\right\} \\
& +2 \sigma \sqrt{\Delta t} \varepsilon(n)+2 \sigma^{2} \Delta t \varepsilon^{2}(n)+O\left(e_{2}[\varepsilon(n)] / n^{1.5}\right) \\
= & 4 \sigma \sqrt{\Delta t}[\varepsilon(n)-0.5]+2 \sigma^{2} \Delta t(1-\varepsilon(n))^{2}-8 b \sigma \Delta t(1-\varepsilon(n)) \\
& +\frac{4 \ln (X / S)}{n}(1-\varepsilon(n))+2 \sigma^{2} \Delta t \varepsilon^{2}(n)+O\left(e_{4}[\varepsilon(n)] / n^{1.5}\right) .
\end{aligned}
$$

On the other hand, according to Feller (1971, pp. 53-54), $n !=\sqrt{2 \pi} n^{n+\frac{1}{2}} e^{-n}(1+O(1 / n))$.

Therefore, we obtain

$$
C_{m}^{n}=\frac{1}{\sqrt{2 \pi n}} \frac{1}{\left(1-\frac{m}{n}\right)^{n-m+\frac{1}{2}}\left(\frac{m}{n}\right)^{m+\frac{1}{2}}}(1+O(1 / n))
$$


Since $m / n=1 / 2+z / n$ according to (A2), we have

$$
C_{m}^{n}=\frac{1}{\sqrt{2 \pi n}} \cdot \frac{(1+O(1 / n))}{\left(\frac{1}{2}\right)^{n+1}\left(1-\frac{2 z}{n}\right)^{n-m+\frac{1}{2}}\left(1+\frac{2 z}{n}\right)^{m+\frac{1}{2}}}
$$

On the other hand, using (A3), we obtain

$$
p^{m}(1-p)^{n-m}=\left(\frac{1}{2}\right)^{n}(1+x)^{m}(1-x)^{n-m}
$$

where $x=2 b \sqrt{\Delta t}+O(1 / n)$. Therefore, combining (A13) and (A14) gives

$$
\begin{aligned}
C_{m}^{n} p^{m}(1-p)^{n-m} & =\frac{1}{\sqrt{2 \pi n}} \frac{1}{\left(\frac{1}{2}\right)} \cdot\left(\frac{1-x}{1-\frac{2 z}{n}}\right)^{n-m}\left(\frac{1+x}{1+\frac{2 z}{n}}\right)^{m} \frac{1}{\left(1-\frac{2 z}{n}\right)^{\frac{1}{2}}\left(1+\frac{2 z}{n}\right)^{\frac{1}{2}}} \\
& =\frac{1}{\sqrt{\frac{n \pi}{2}}} \times\left(\frac{1-x}{1-\frac{2 z}{n}}\right)^{n}\left(\frac{1+x}{1-x} \times \frac{1-\frac{2 z}{n}}{1+\frac{2 z}{n}}\right)^{m} \times(1+O(1 / n)) .
\end{aligned}
$$

According to the Taylor series expansion of $\ln (1-y)=-\left(y+\frac{y^{2}}{2}+\frac{y^{3}}{3}+\ldots\right)$ and the definitions of $z$ and $x$ in (A2) and (A14), one can show that

$$
\begin{aligned}
\ln \left(\frac{1-x}{1-\frac{2 z}{n}}\right)^{n}\left(\frac{1+x}{1-x} \times \frac{1-\frac{2 z}{n}}{1+\frac{2 z}{n}}\right)^{m} & =\frac{-n x^{2}}{2}+2 x z-\frac{2 z^{2}}{n}+O(1 / \sqrt{n}) \\
& =-2\left(b \sqrt{\Delta t} \cdot \sqrt{n}-\frac{z}{\sqrt{n}}\right)^{2}+O(1 / \sqrt{n}) .
\end{aligned}
$$

Since

$$
\begin{aligned}
b \sqrt{\Delta t} \sqrt{n}-\frac{z}{\sqrt{n}} & =\frac{\left(r-q-0.5 \times \sigma^{2}\right)}{2 \sigma} \sqrt{T}-\frac{\ln (X / S)}{2 \sigma \sqrt{T}}+\frac{(1-\varepsilon(n))}{\sqrt{n}} \\
& =\frac{1}{2}\left(d_{2}+\frac{2(1-\varepsilon(n))}{\sqrt{n}}\right)
\end{aligned}
$$


we have

$$
\begin{aligned}
(A 16) & =-\frac{\left(d_{2}+\frac{2(1-\varepsilon(n))}{\sqrt{n}}\right)^{2}}{2}+O(1 / \sqrt{n}) \\
& =-\frac{d_{2}^{2}}{2}-\frac{2 d_{2}(1-\varepsilon(n))}{\sqrt{n}}+O(1 / \sqrt{n})
\end{aligned}
$$

Therefore,

$$
\begin{aligned}
X e^{-r T} C_{m}^{n} p^{m}(1-p)^{n-m} & =X e^{-r T} \frac{e^{\frac{-d_{2}^{2}}{2}} e^{\frac{-2 d_{2}(1-\varepsilon(n))}{\sqrt{n}}}}{\sqrt{\frac{n \pi}{2}}} \cdot[1+O(1 / \sqrt{n})][1+O(1 / n)] \\
& =S e^{-q T} \frac{e^{\frac{-d_{1}^{2}}{2}} e^{\frac{-2 d_{2}(1-\varepsilon(n))}{\sqrt{n}}}}{\sqrt{\frac{n \pi}{2}}}[1+O(1 / \sqrt{n})][1+O(1 / n)] .
\end{aligned}
$$

From Equations (A12) and (A17), $A+B$ in (A8) is given by

$$
\begin{aligned}
(A+B)= & S e^{-q T} \frac{1}{\sqrt{\frac{\pi n}{2}}} e^{\frac{-d_{1}^{2}}{2}} \cdot e^{\frac{-2 d_{2}(1-\varepsilon(n))}{\sqrt{n}}}[1+O(1 / \sqrt{n})][1+O(1 / n)] \\
& \times\left\{4 \sigma \sqrt{\Delta t}[\varepsilon(n)-0.5]+2 \sigma^{2} \Delta t(1-\varepsilon(n))^{2}-8 b \sigma \Delta t(1-\varepsilon(n))\right. \\
& \left.+\frac{4 \ln (X / S)}{n}(1-\varepsilon(n))+2 \sigma^{2} \Delta t \varepsilon^{2}(n)+O\left(e_{4}[\varepsilon(n)] / n^{1.5}\right)\right\} .
\end{aligned}
$$

Consequently,

$$
\hat{\Delta}_{n, \mathrm{CRR}}=\frac{(A 4)-(A 5)}{S\left(u^{2}-d^{2}\right)}=\frac{A+B+C}{S\left(u^{2}-d^{2}\right)}=\frac{(A 18)}{S\left(u^{2}-d^{2}\right)}+(A 7) .
$$

After tedious calculations, we have

$$
\hat{\Delta}_{n, \text { CRR }}=-e^{-q T} N\left(-d_{1}\right)+e^{-q T} \frac{e^{-d_{1}^{2} / 2}}{n \sqrt{2 \pi}} f(\varepsilon(n))+O(1 / n)
$$

where $f(\varepsilon(n))=2 d_{2}\left[-\varepsilon(n)+\varepsilon^{2}(n)\right]$.

\section{Proof of Theorem 2}

We next prove the rate of convergence for the smoothed payoff (SPF) approach of Heston and Zhou (2000). Note that the SPF method can be implemented with any binomial models and the proof here is for the case under the CRR 
model with $\varepsilon(n)<0.5$. The proof for the other case under the CRR model with $\varepsilon(n) \geq 0.5$ is similar and available upon request.

According to (7), the current option value at node $S_{0,1}=S u^{2}$ under the SPF approach can be decomposed as the following:

$$
\begin{aligned}
& e^{-r T} \sum_{j=0}^{m-1} C_{j}^{n} p^{j}(1-p)^{n-j}\left(X-S u^{2} u^{j} d^{n-j}\right) \\
& +e^{-r T} \sum_{j=0}^{m-1} C_{j}^{n} p^{j}(1-p)^{n-j}\left(S u^{2} u^{j} d^{n-j}-S u^{2} u^{j} d^{n-j} \frac{e^{\sigma \sqrt{\Delta t}}-e^{-\sigma \sqrt{\Delta t}}}{2 \sigma \sqrt{\Delta t}}\right) \\
& +e^{-r T} C_{m}^{n} p^{m}(1-p)^{n-m}\left\{\frac{X\left[\sigma \sqrt{\Delta t}-\ln \left(S u^{m+1} d^{n-m-1} / X\right)\right]+e^{-\sigma \sqrt{\Delta t}} S u^{m+1} d^{n-m-1}-X}{2 \sigma \sqrt{\Delta t}}\right\} .
\end{aligned}
$$

This first term in (A20) is the same as (A4) in the CRR model without adopting the SPF approach. The second term is to adjust the difference between the actual payoff, $X-S_{T}$, and the smoothed payoff, $X-S_{T}\left(e^{\sigma \sqrt{\Delta t}}-e^{-\sigma \sqrt{\Delta t}}\right) / 2 \sigma \sqrt{\Delta t}$, at the nodes where $\ln S_{T}-\ln X<-\sigma \sqrt{\Delta t}$ (i.e. node $S_{x}$ and all nodes below it since $\varepsilon(n)<0.5)$. Similarly, the third term is to adjust the difference between the actual payoff, 0 , and the smoothed payoff, $\frac{X\left(\sigma \sqrt{\Delta t}-\ln \left(S_{T} / X\right)\right)+S_{T} e^{-\sigma \sqrt{\Delta t}}-X}{2 \sigma \sqrt{\Delta t}}$, at node $S_{x+1}$. Note that the second term can be expressed as

$$
e^{-r T} \sum_{j=0}^{m-1} C_{j}^{n} p^{j}(1-p)^{n-j} S u^{2} u^{j} d^{n-j}\left(1-\frac{e^{\sigma \sqrt{\Delta t}}-e^{-\sigma \sqrt{\Delta t}}}{2 \sigma \sqrt{\Delta t}}\right)=O_{1}(1 / n) .
$$

Thus, (A20) can be simplified further as follows

$$
e^{-r T} \sum_{j=0}^{m-1} C_{j}^{n} p^{j}(1-p)^{n-j}\left(X-S u^{2} u^{j} d^{n-j}\right)+X e^{-r T} C_{m}^{n} p^{m}(1-p)^{n-m} A^{*}+O_{1}(1 / n)
$$

where

$$
A^{*}=\frac{\left[\sigma \sqrt{\Delta t}-\ln \left(S u^{m+1} d^{n-m-1} / X\right)\right]+e^{-\sigma \sqrt{\Delta t}} S u^{m+1} d^{n-m-1} / X-1}{2 \sigma \sqrt{\Delta t}} .
$$

Similarly, the option value at node $S_{0,-1}=S d^{2}$ is

$$
\begin{aligned}
e^{-r T} & \sum_{j=0}^{m+1} C_{j}^{n} p^{j}(1-p)^{n-j}\left(X-S d^{2} u^{j} d^{n-j}\right) \\
& +X e^{-r T} C_{m+2}^{n} p^{m+2}(1-p)^{n-m-2} A^{*}+O_{2}(1 / n) .
\end{aligned}
$$


Then, the delta estimate under the SPF method equals ${ }^{25}$

$$
\begin{aligned}
\hat{\Delta}_{n, \mathrm{SPF}} & =\frac{(\mathrm{A} 21)-(\mathrm{A} 22)}{S\left(u^{2}-d^{2}\right)} \\
& =\hat{\Delta}_{n, \mathrm{C} R R}+\frac{X e^{-r \mathrm{~T}} A^{*}\left[C_{m}^{n} p^{m}(1-p)^{n-m}-C_{m+2}^{n} p^{m+2}(1-p)^{n-m-2}\right]}{S\left(u^{2}-d^{2}\right)}+O(1 / n) .
\end{aligned}
$$

Because $\ln \frac{S u^{m+1} d^{n-m-1}}{X}=2 \sigma \sqrt{\Delta t} \varepsilon(n)$, we have

$$
A^{*}=\left[\frac{1}{2}-\varepsilon(n)\right]+\frac{\left[e^{\sigma \sqrt{\Delta t}(2 \varepsilon(n)-1)}-1\right]}{2 \sigma \sqrt{\Delta t}}=\sigma \sqrt{\Delta t}[\varepsilon(n)-0.5]^{2}+O\left(E_{1}[\varepsilon(n)] / n\right) .
$$

In addition,

$$
\begin{aligned}
& X e^{-r T}\left[C_{m}^{n} p^{m}(1-p)^{n-m}-C_{m+2}^{n} p^{m+2}(1-p)^{n-m-2}\right] \\
& \quad=X e^{-r T} C_{m}^{n} p^{m}(1-p)^{n-m}\left[1-\frac{(n-m-1)(n-m)}{(m+1)(m+2)} \frac{p^{2}}{(1-p)^{2}}\right] .
\end{aligned}
$$

Since

$$
\begin{aligned}
& p=\frac{1}{2}+b \sqrt{\Delta t}+O(1 / n) \quad \text { and } \\
& \frac{(n-m-1)(n-m)}{(m+1)(m+2)}=\frac{\left[1-\frac{2(z+1)}{n}\right]\left[1-\frac{2 z}{n}\right]}{\left[1+\frac{2(z+1)}{n}\right]\left[1+\frac{2(z+2)}{n}\right]}
\end{aligned}
$$

where $b=\frac{r-q-\sigma^{2} / 2}{2 \sigma}$ and $z=\frac{\ln (X / S)}{2 \sigma \sqrt{\Delta t}}-(1-\varepsilon(n))$, we see that

${ }^{25}$ According to (A21) and (A22),

$$
\begin{aligned}
O_{1}(1 / n) & -O_{2}(1 / n)=e^{-r T}\left(\sum_{j=0}^{m-1} C_{j}^{n} p^{j}(1-p)^{n-j} S u^{2} u^{j} d^{n-j}\right. \\
& \left.-\sum_{j=0}^{m+1} C_{j}^{n} p^{j}(1-p)^{n-j} S d^{2} u^{j} d^{n-j}\right)\left(1-\frac{e^{\sigma \sqrt{\Delta t}}-e^{-\sigma \sqrt{\Delta t}}}{2 \sigma \sqrt{\Delta t}}\right) .
\end{aligned}
$$

Therefore, $\frac{O_{1}(1 / n)-O_{2}(1 / n)}{S\left(u^{2}-d^{2}\right)}=O(1 / n)$. 


$$
\begin{aligned}
{[1} & \left.-\frac{(n-m-1)(n-m)}{(m+1)(m+2)} \frac{p^{2}}{(1-p)^{2}}\right] \\
& =\frac{4 \ln (X / S)}{n \sigma \sqrt{\Delta t}}-4 \frac{\left(r-q-\frac{\sigma^{2}}{2}\right)}{\sigma} \sqrt{\Delta t}+O\left(E_{2}[\varepsilon(n)] / n\right) \\
& =\frac{-4 d_{2}}{\sqrt{n}}+O\left(E_{1}[\varepsilon(n)] / n\right) .
\end{aligned}
$$

Substituting (A17) and (A26) into (A25) yields

$$
\begin{aligned}
(A 25)= & S e^{-q T} \frac{e^{\frac{-d_{1}^{2}}{2}} e^{\frac{-2 d_{2}(1-\varepsilon(n))}{\sqrt{n}}}}{\sqrt{\frac{\pi n}{2}}}(1+O(1 / \sqrt{n}))[1+O(1 / n)] \\
& \times\left[\frac{-4 d_{2}}{\sqrt{n}}+O\left(E_{2}[\varepsilon(n)] / n\right)\right]
\end{aligned}
$$

Therefore, by (A24) and (A27), we have

$$
\begin{gathered}
\frac{X e^{-r T} A^{*}\left[C_{m}^{n} p^{m}(1-p)^{n-m}-C_{m+2}^{n} p^{m+2}(1-p)^{n-m-2}\right]}{S\left(u^{2}-d^{2}\right)} \\
=e^{-q T} \frac{2 e^{-d_{1}^{2} / 2}}{n \sqrt{2 \pi}}\left(-d_{2}\right)[\varepsilon(n)-0.5]^{2}+O\left(E_{3}[\varepsilon(n)] / n^{1.5}\right) \\
=e^{-q T} \frac{2 e^{-d_{1}^{2} / 2}}{n \sqrt{2 \pi}}\left(-d_{2}\right)\left[-\varepsilon(n)+\varepsilon^{2}(n)\right]+O(1 / n) .
\end{gathered}
$$

Thus, substituting (A19) and (A28) into (A23) gives

$$
\hat{\Delta}_{n, S P F}=-e^{-q T} N\left(-d_{1}\right)+O(1 / n) .
$$

\section{Proof of Theorem 3}

We finally prove the convergence rate for the GCRR-XPC model. Note that, in this model, the stretch parameter depends on $n$ because it must satisfy a constraint that the strike price is placed at the center of the final nodes node, i.e. $S u^{n / 2} d^{n / 2}=K$. Denote the stretch parameter as $\lambda(n)$ thus $u=e^{\lambda(n) \sigma \sqrt{\Delta t}}$, $d=e^{-\sigma \sqrt{\Delta t} / \lambda(n)}$, and $p=\frac{e^{(r-q) \Delta t}-d}{u-d}$ in the GCRR-XPC model. Similarly, the European put option values under the GCRR-XPC model at nodes $S_{0,1}=S u / d$ and $S_{0,-1}=S d / u$ are, respectively, given by 


$$
\begin{aligned}
C_{0,1} & =e^{-r T} \sum_{j=0}^{\frac{n}{2}-1} C_{j}^{n} p^{j}(1-p)^{n-j}\left(X-\frac{S u}{d} u^{j} d^{n-j}\right) \\
C_{0,-1} & =e^{-r T} \sum_{j=0}^{\frac{n}{2}+1} C_{j}^{n} p^{j}(1-p)^{n-j}\left(X-\frac{S d}{u} u^{j} d^{n-j}\right) .
\end{aligned}
$$

The delta estimate is defined as $\hat{\Delta}_{n, G C R R-X P C}=\frac{(A 29)-(A 30)}{S(u / d-d / u)}$ and

$$
\begin{aligned}
& \text { (A29) }-\left(\text { A30) }=X\left[\sum_{j=0}^{\frac{n}{2}-1} C_{j}^{n} p^{j}(1-p)^{n-j}-\sum_{j=0}^{\frac{n}{2}+1} C_{j}^{n} p^{j}(1-p)^{n-j}\right] e^{-r T}\right. \\
& +\left[\sum_{j=0}^{\frac{n}{2}+1} \frac{S d}{u} u^{j} d^{n-j} C_{j}^{n} p^{j}(1-p)^{n-j}-\sum_{j=0}^{\frac{n}{2}-1} \frac{S u}{d} u^{j} d^{n-j} C_{j}^{n} p^{j}(1-p)^{n-j}\right] e^{-r T} .
\end{aligned}
$$

Because

$$
C_{(n / 2)+1}^{n}=\frac{n !}{\left(\frac{n}{2}+1\right) !\left(\frac{n}{2}-1\right) !}=\frac{n !}{\left(\frac{n}{2}\right) !\left(\frac{n}{2}\right) !} \cdot \frac{n / 2}{\frac{n}{2}+1}=C_{(n / 2)}^{n} \frac{n}{n+2}
$$

we obtain

$$
\begin{aligned}
& X\left[\sum_{j=0}^{n} C_{j}^{n} p^{j}(1-p)^{n-j}-\sum_{j=0}^{\frac{n}{2}+1} C_{j}^{n} p^{j}(1-p)^{n-j}\right] e^{-r T} \\
& \quad=-X C_{(n / 2)}^{n} p^{n / 2}(1-p)^{n / 2} \cdot\left[1+\frac{n}{n+2} \cdot \frac{p}{1-p}\right] e^{-r T} .
\end{aligned}
$$
where

According to Chung and Shih (2007, p. 520), $p=\frac{1}{2}+a \sqrt{\Delta t}+O(1 / n)$

$$
\begin{gathered}
a=\frac{1}{2}\left(\frac{r-q}{\sigma}-\frac{\ln (X / S)}{\sigma T}-\frac{\sigma}{2}\right)=\frac{1}{2} \frac{\ln (X / S)+\left(r-q-\sigma^{2} / 2\right) T}{\sigma T}=\frac{1}{2} d_{2} \frac{1}{\sqrt{T}} \\
p^{\frac{n}{2}}(1-p)^{\frac{n}{2}}=\left(\frac{1}{4}\right)^{\frac{n}{2}}\left[1-4 a^{2} \Delta t+O\left(1 / n^{1.5}\right)\right]^{\frac{n}{2}} .
\end{gathered}
$$

On the other hand, 


$$
\begin{aligned}
& {\left[\sum_{j=0}^{\frac{n}{2}+1} \frac{S d}{u} u^{j} d^{n-j} C_{j}^{n} p^{j}(1-p)^{n-j}-\sum_{j=0}^{\frac{n}{2}-1} \frac{S u}{d} u^{j} d^{n-j} C_{j}^{n} p^{j}(1-p)^{n-j}\right] e^{-r T}} \\
& \quad=\sum_{j=0}^{\frac{n}{2}}\left(\frac{S d}{u}-\frac{S u}{d}\right) C_{j}^{n} p^{j}(1-p)^{n-j} u^{j} d^{n-j} e^{-r T} \\
& \quad+\frac{S d}{u} u^{\frac{n}{2}+1} d^{\frac{n}{2}-1} C_{(n / 2)+1}^{n} p^{\frac{n}{2}+1}(1-p)^{\frac{n}{2}-1} e^{-r T}+\frac{S u}{d} u^{\frac{n}{2}} d^{\frac{n}{2}} C_{n / 2}^{n} p^{\frac{n}{2}}(1-p)^{\frac{n}{2}} \cdot e^{-r T} \\
& \quad S^{\frac{S d}{u}} u^{\frac{n}{2}+1} d^{\frac{n}{2}-1} C_{(n / 2)+1}^{n} p^{\frac{n}{2}+1}(1-p)^{\frac{n}{2}-1} e^{-r T}+\frac{S u}{d} u^{\frac{n}{2}} d^{\frac{n}{2}}=X \text { and } C_{n / 2}^{n} p^{\frac{n}{2}}(1-p)^{\frac{n}{2}} \cdot e^{-r T} \\
& =C_{n / 2}^{n} p^{\frac{n}{2}}(1-p)^{\frac{n}{2}} \cdot X \cdot\left[\frac{u}{d}+\frac{p}{1-p} \cdot \frac{n}{n+2}\right] \cdot e^{-r T} \cdot
\end{aligned}
$$

From (A31), (A34), and (A35), we get

$$
\begin{aligned}
\frac{(A 29)-(A 30)}{S(u / d-d / u)}=- & \sum_{j=0}^{n / 2} C_{j}^{n} p^{j}(1-p)^{n-j} u^{j} d^{n-j} \cdot e^{-r T} \\
& +\frac{X C_{n / 2}^{n} p^{\frac{n}{2}}(1-p)^{\frac{n}{2}}(u / d-1)}{S(u / d-d / u)} \cdot e^{-r T} .
\end{aligned}
$$

Because $p(1-p)=\left(\frac{1}{2}\right)^{2}-(a \sqrt{\Delta t}+O(1 / n))^{2}=\frac{1}{4}[1-x]$, where $x=4 a^{2} \Delta t+$ $O\left(1 / n^{1.5}\right)$, we find that

$$
\frac{X C_{n / 2}^{n} p^{\frac{n}{2}}(1-p)^{\frac{n}{2}}(u / d-1)}{S(u / d-d / u)} \cdot e^{-r T}=\frac{X}{S} C_{n / 2}^{n}\left(\frac{1}{4}\right)^{n / 2}(1-x)^{n / 2} \frac{(u / d-1)}{(u / d-d / u)} e^{-r T} .
$$

Since $(1-x)^{n / 2}=e^{\frac{n}{2} \ln (1-x)}=e^{-\frac{n}{2}\left(x+\frac{x^{2}}{2}+\cdots\right)}=e^{-2 a^{2} n \Delta t} e^{O(1 / \sqrt{n})}$, by the definition of $a$ in (A32) and $e^{\frac{-d_{2}^{2}}{2}}=e^{\frac{-\left(d_{1}-\sigma \sqrt{T}\right)^{2}}{2}}=e^{\frac{-d_{1}^{2}}{2}} e^{(r-q) T}(S / X),{ }^{26}$ we have

$$
(1-x)^{n / 2}=e^{\frac{-d_{2}^{2}}{2}} \cdot e^{O(1 / \sqrt{n})}=(S / X) e^{\frac{-d_{1}^{2}}{2}} \cdot e^{(r-q) T} \cdot e^{O(1 / \sqrt{n})} .
$$

Thus,

$$
\frac{X C_{n / 2}^{n} p^{\frac{n}{2}}(1-p)^{\frac{n}{2}}(u / d-1)}{S(u / d-d / u)} \cdot e^{-r T}=e^{-q T} C_{n / 2}^{n}\left(\frac{1}{4}\right)^{\frac{n}{2}} e^{\frac{-d_{1}^{2}}{2}} e^{O(1 / \sqrt{n})} \frac{(u / d-1)}{(u / d-d / u)} .
$$

${ }^{26}$ The last equality comes from that fact that $d_{1} \sigma \sqrt{T}-\sigma^{2} T / 2=\ln (S / X)+(r-q) T$. 
According to Feller's (1971, pp. 53-54), $n !=\sqrt{2 \pi} \cdot n^{n+\frac{1}{2}} e^{-n}(1+O(1 / n))$. Consequently, $C_{n / 2}^{n}\left(\frac{1}{4}\right)^{\frac{n}{2}}=\frac{1}{\sqrt{n \pi / 2}}[1+O(1 / n)]$ and (A38) becomes

$$
\begin{aligned}
& \frac{X C_{n / 2}^{n} p^{\frac{n}{2}}(1-p)^{\frac{n}{2}}(u / d-1)}{S(u / d-d / u)} \cdot e^{-r T} \\
& =e^{-q T} e^{\frac{-d_{1}^{2}}{2}} \frac{1}{\sqrt{2 \pi \cdot(n / 4)}}[1+O(1 / n)] \cdot e^{O(1 / \sqrt{n}) \cdot \frac{(u / d-1)}{(u / d-d / u)}} \\
& =e^{-q T} e^{\frac{-d_{1}^{2}}{2}} \frac{1}{\sqrt{2 \pi \cdot(n / 4)}}[1+O(1 / n)] \cdot[1+O(1 / \sqrt{n})] \cdot\left[\frac{1}{2}+O(1 / \sqrt{n})\right] \\
& =\frac{1}{2} e^{-q T} e^{\frac{-d_{1}^{2}}{2}} \frac{1}{\sqrt{2 \pi \cdot(n / 4)}}+O(1 / n) .
\end{aligned}
$$

According to Chung and Shih (2007, p. 520)

$$
\sum_{J=0}^{n / 2} C_{j}^{n} p^{* j}\left(1-p^{*}\right)^{n-j}=N\left(-d_{1}+\frac{0.5}{\sqrt{n p^{*}\left(1-p^{*}\right)}}\right)+O(1 / n)
$$

where $p^{*}=\frac{p u}{e^{(r-q) \Delta t}}$. Thus, the first term in (A36) can be rewritten as

$$
\begin{gathered}
-\sum_{J=0}^{n / 2} C_{j}^{n} p^{j}(1-p)^{n-j} u^{j} d^{n-j} e^{-r T}=-e^{-q T} \sum_{J=0}^{n / 2} C_{j}^{n} p^{* j}\left(1-p^{*}\right)^{n-j} \\
=-e^{-q T} N\left(-d_{1}+\frac{0.5}{\sqrt{n p^{*}\left(1-p^{*}\right)}}\right)+O(1 / n) \\
=-e^{-q T} N\left(-d_{1}\right)-e^{-q T} \frac{1}{\sqrt{2 \pi}} e^{\frac{-d_{1}^{2}}{2}} \frac{0.5}{\sqrt{n / 4}}+O(1 / n)
\end{gathered}
$$

where the third equality comes from the first order Taylor expansion and $p^{*}=\frac{1}{2}+O(1 / \sqrt{n})$. Substituting $(\mathrm{A} 39)$ and (A40) into (A36) yields

$$
\hat{\Delta}_{n, G C R R-X P C}=\frac{(A 29)-(A 30)}{S(u / d-d / u)}=-e^{-q T} N\left(-d_{1}\right)+O(1 / n) .
$$

\section{BIBLIOGRAPHY}

Broadie, M., \& Detemple, J. (1996). American option valuation: New bounds, approximations, and a comparison of existing methods. Review of Financial Studies, 9, $1211-1250$. 
Chang, C. C., Chung, S. L., \& Stapleton, R. (2007). Richardson extrapolation techniques for the pricing of American-style options. Journal of Futures Markets, 27, 791-817.

Chung, S. L., \& Shackleton, M. (2002). The binomial Black-Scholes model and the Greeks. Journal of Futures Markets, 22, 143-153.

Chung, S. L., \& Shih, P. T. (2007). Generalized Cox-Ross-Rubinstein binomial model. Management Science, 53, 508-520.

Cox, J. C., Ross, A., \& Rubinstein, M. (1979). Option pricing: A simplified approach. Journal of Financial Economics, 7, 229-263.

Feller, W. (1971). An Introduction to Probability Theory and Its Applications. NY: Wiley.

Figlewski, S., \& Gao, B. (1999). The adaptive mesh model: A new approach to efficient option pricing. Journal of Financial Economics, 53, 313-351.

Heston, S., \& Zhou, G. (2000). On the rate of convergence of discrete-time contingent claims. Mathematical Finance, 10, 53-75.

Hull, J. C. (2006). Options, Futures, and Other Derivatives (6th ed.). Upper Saddle River, NJ: Prentice Hall.

Leisen, D. (1998). Pricing the American put option: A detailed convergence analysis for binomial models. Journal of Economic Dynamics and Control, 22, 1419-1444.

Leisen, D., \& Reimer, M. (1996). Binomial models for option valuation-examining and improving convergence. Applied Mathematical Finance, 3, 319-346.

Omberg, E. (1988). Efficient discrete time jump process models in option pricing. Journal of Financial and Quantitative Analysis, 23, 161-174.

Pelsser, A., \& Vorst, T. (1994). The binomial model and the Greeks. Journal of Derivatives, 1, 45-49.

Rendleman, R., \& Batter, B. (1979). Two-state option pricing. Journal of Finance, 34, 1093-1110.

Tian, Y. S. (1999). A flexible binomial option pricing model. Journal of Futures Markets, 19, 817-843.

Widdicks, M., Andricopoulos, A. D., Newton, D. P., \& Duck, P. W. (2002). On the enhanced convergence of standard lattice methods for option pricing. Journal of Futures Markets, 22, 315-338. 